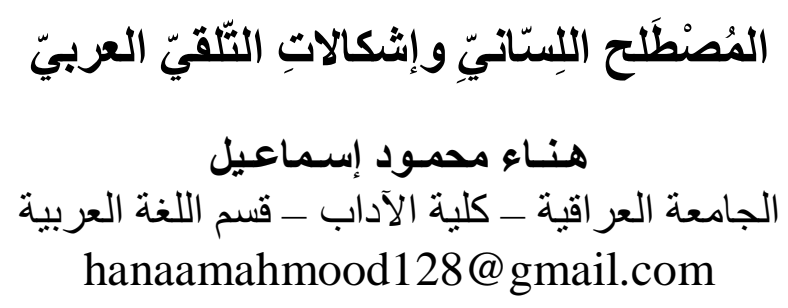

DOI: https://doi.org/10.36231/coedw/vol30no3.6

Received 11/6/2019 Accepted 1/9/2019

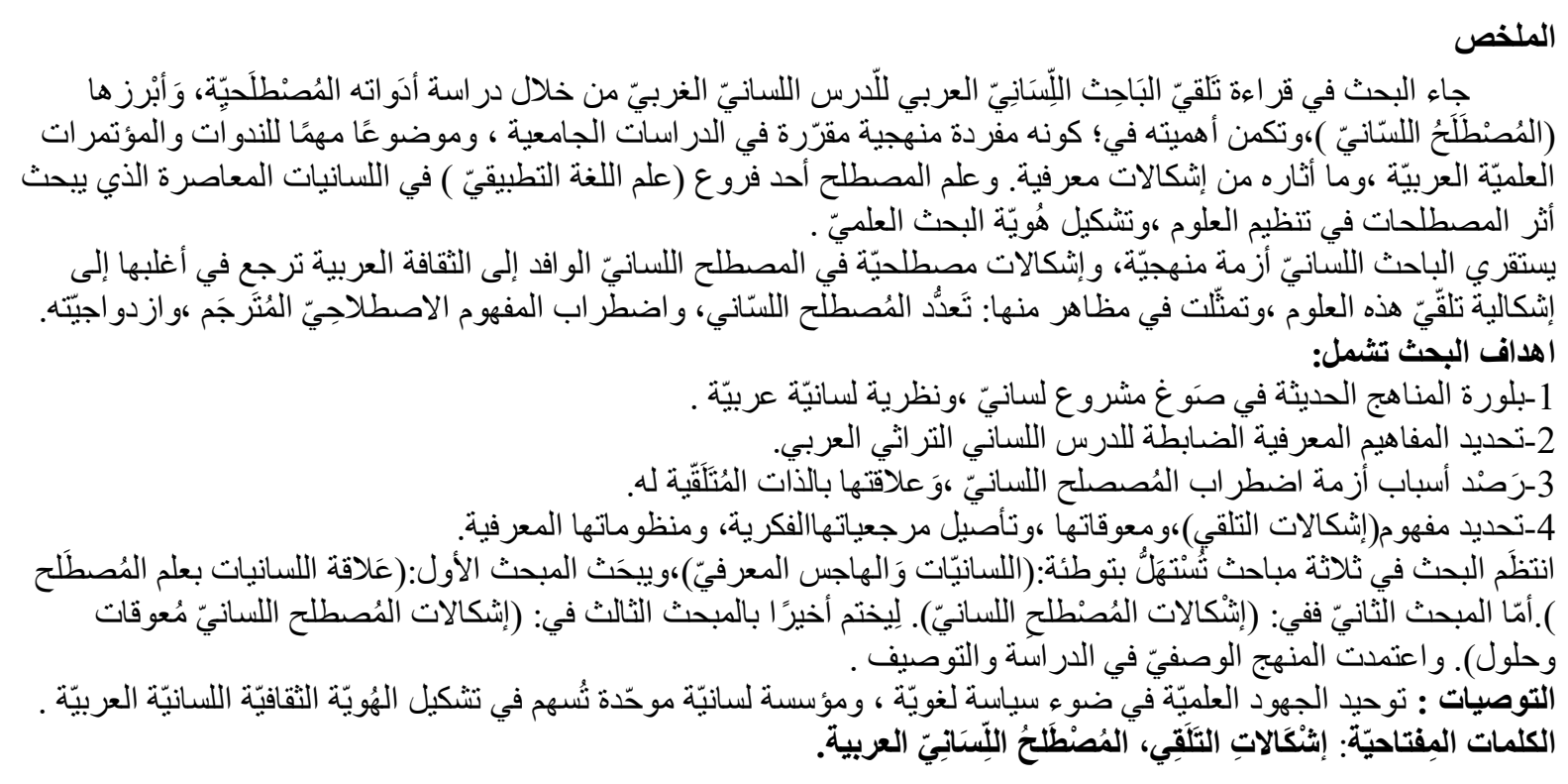

\title{
The Linguistic Term and the Problems of the Arabic Reception
}

\section{Hanaa Mahmood Ismail}

Al-Iraqia University -College of Arts- Department of Arabic Language

\section{Abstract}

The linguistic researcher reads a systematic crisis, idiomatic problems within the linguistic term coming to the Arab culture. Where most of them return back to problems of receiving these sciences which are represented by phenomena like the multiplicity linguistic term, disturbance translated idiomatic concept and its duality .

\section{Aims of the research :}

1-Initializing new textbooks to form linguistic project and Arabic linguistic theory.

2-Determination adjusted knowledge, concepts of Arabian heritage linguistics subject

3-Observation the causes of disturbance crisis of linguistic term and its relation to the self-receiver .

4- The specification concept of ( Receiving Problems), its obstructions, originate its intellectual references and its knowledge system .

This research is organized within three parts to be initiated with the preamble: ( Linguistics \& Knowledge Obsession). Part one discusses ( Relation of linguistics with terminology). Whereas the second part discusses ( Problems of the linguistic term). The last one is concerned with : (Problems of Linguistic term as obstructions and solutions). And it followed the descriptive way to study and explanation.

Recommendations: Unifying scientific efforts in the light of linguistic policy, unified linguistic foundation to form the Arabian linguistic-cultural identity.

Key words : receiving problems, Linguistics, Arabic language 


\section{توطئة: اللسانيّات و الهاجس المَعرفيّ}

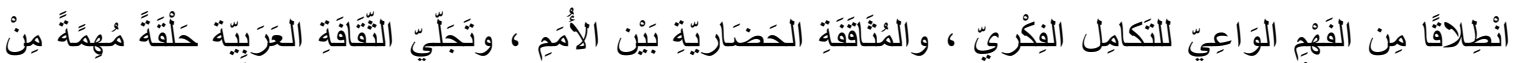

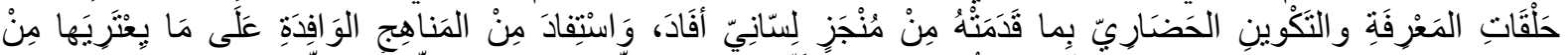

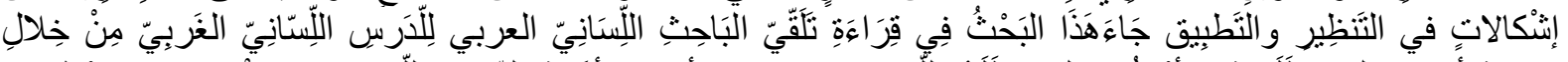

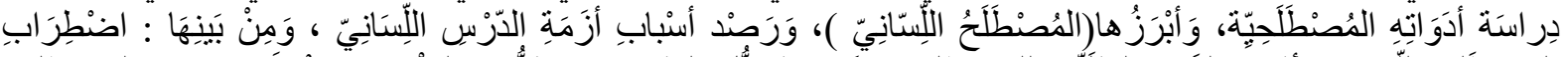

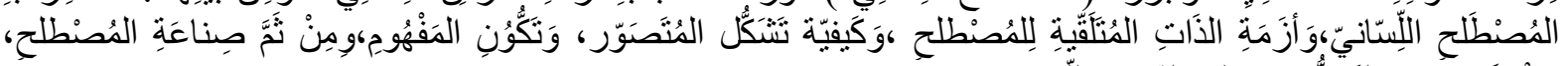

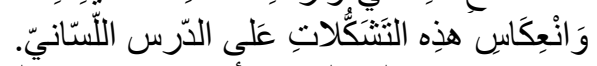

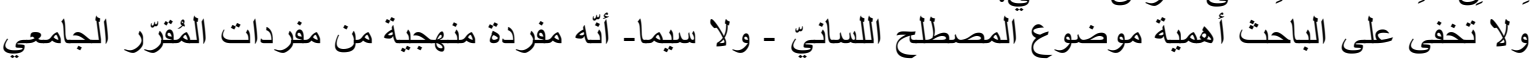

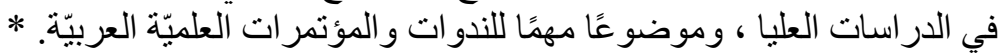

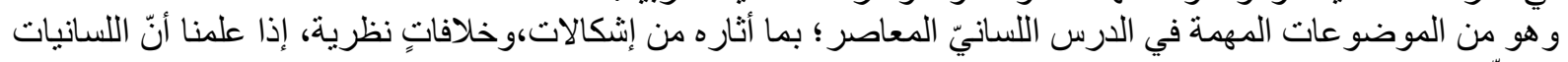

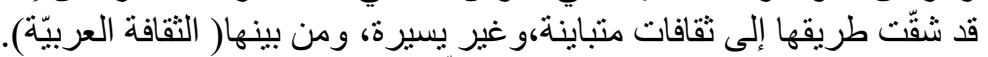

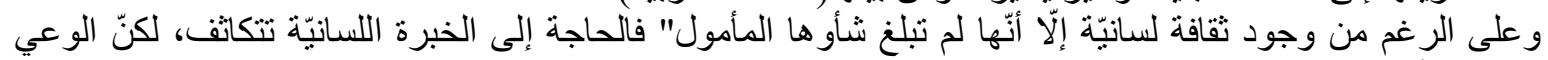

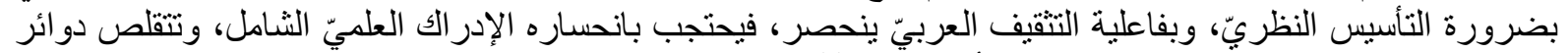

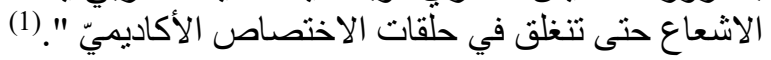

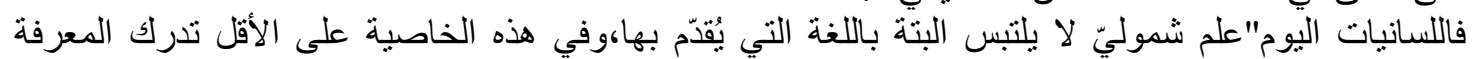

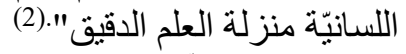

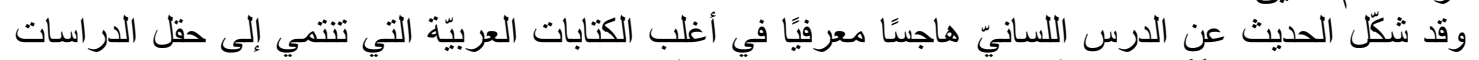

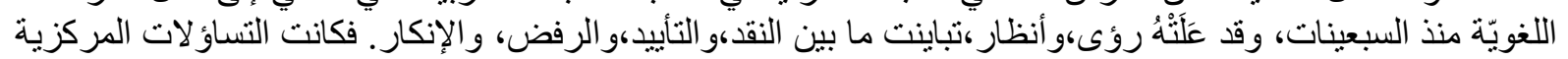

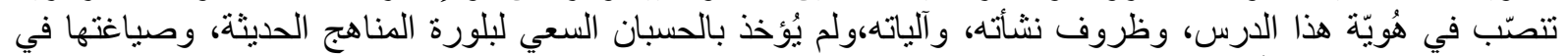

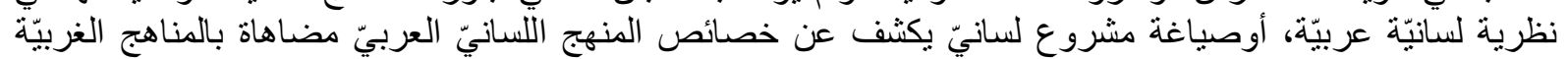

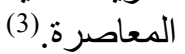

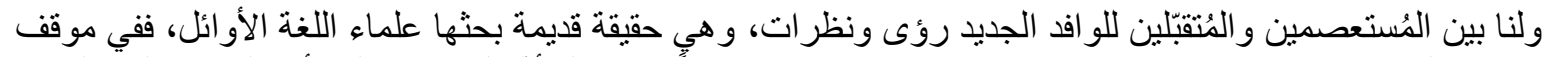

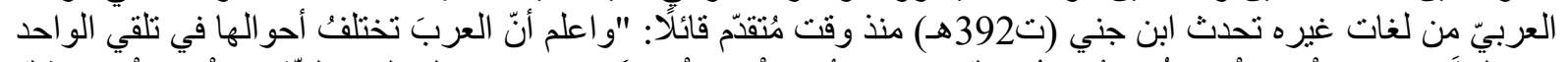

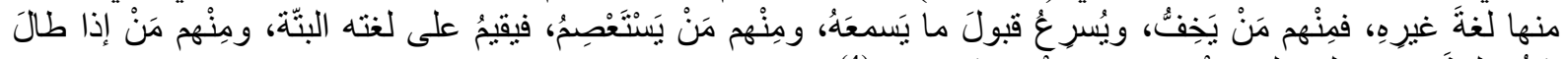

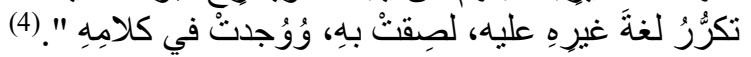

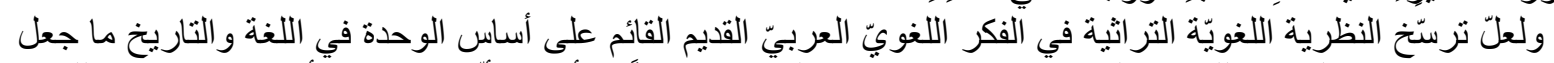

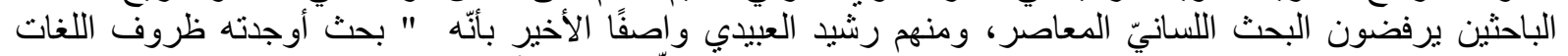

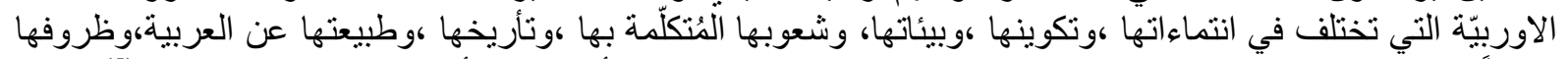

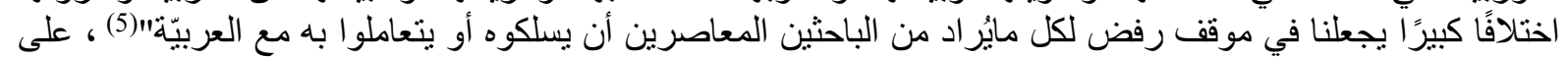

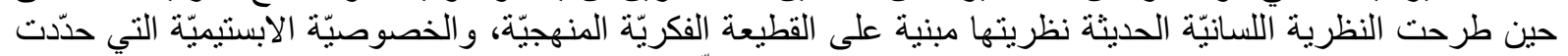

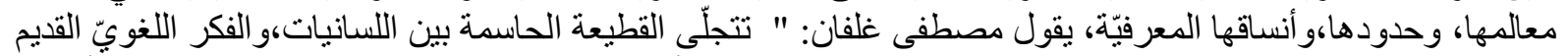

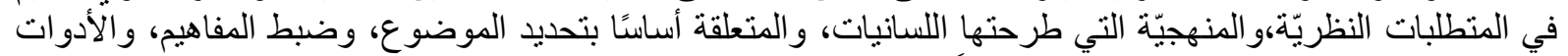

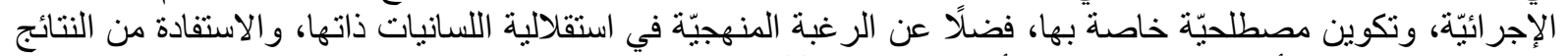

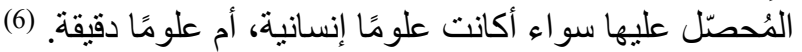
ومن جانب آخر انصهرت الأنظار اللسانيّة المعاصرة في النيّة الامتداد المعرفيّ المستقبليّ ؛ ليتجاوز حدود الزمان والمكان؛

ما ذهب إليه حافظ اسماعيلي علوي:"لا يصح وضع فاصل معرفيّ بين العمل اللسانيّ القديم والحديث، فالبحث اللسانيّ

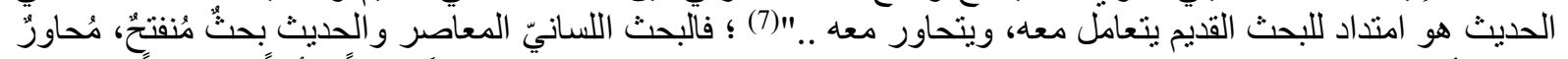

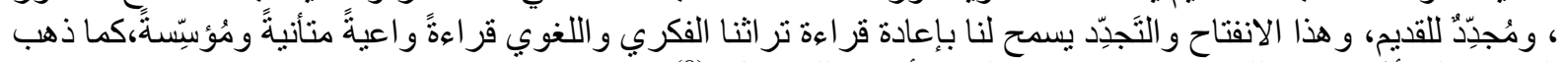

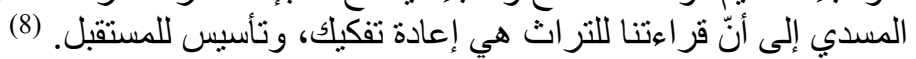
وايرى بعض اللسانيين أنّ أزمة الدرس إعاد اللسانيّ في المعرفة الحديثة تكمن في وجود هذا العلم وصر اعه مع التراث ؛فهي

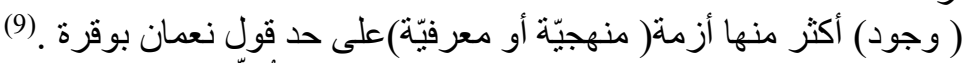

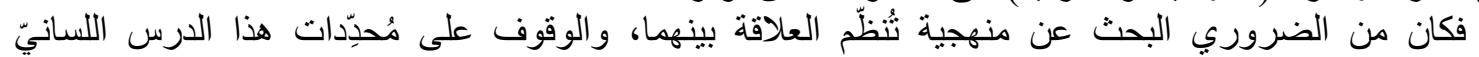

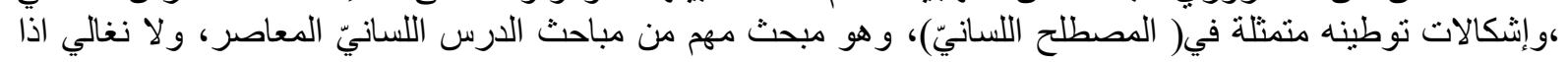


ماقلنا أنّه جو هره وصلبه، والحديث عنه يحيلنا إلى مبحثين مهين و هما :(علم المصطلح)، و الثاني (اللسانيات) بوصفها

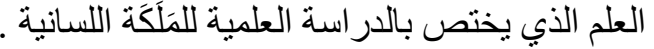

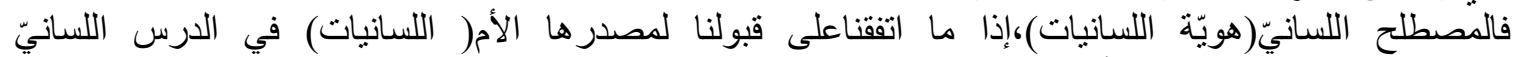

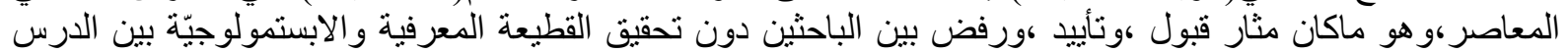

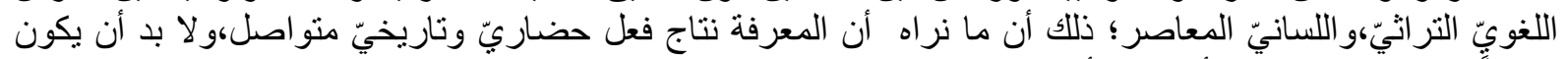

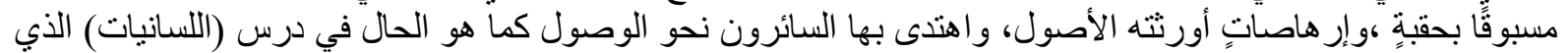

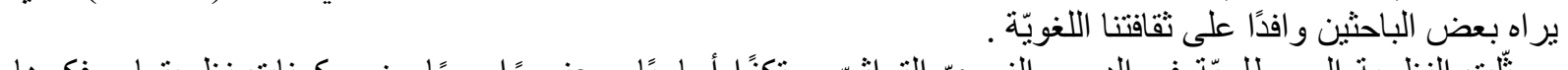

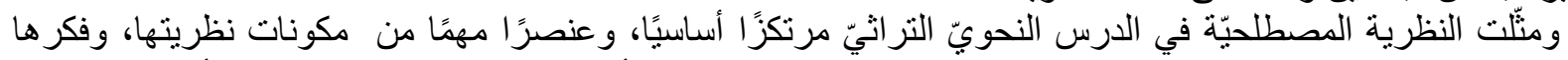

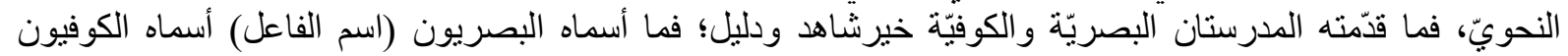

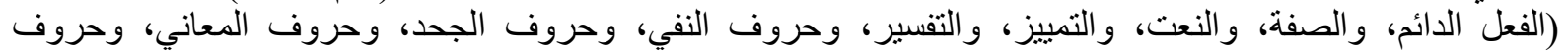

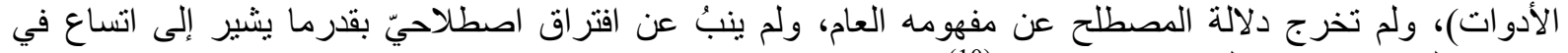

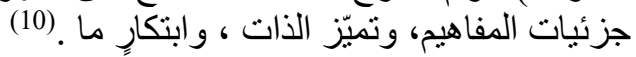

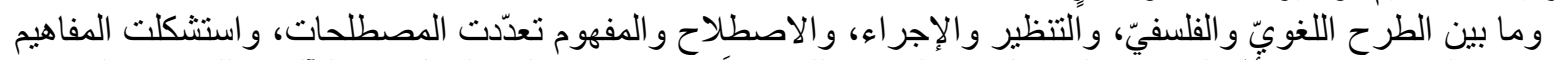

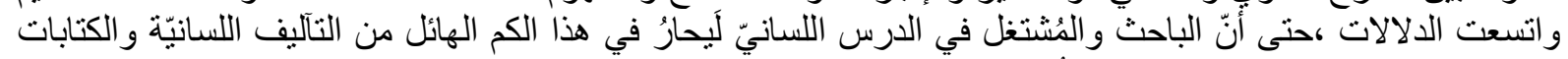

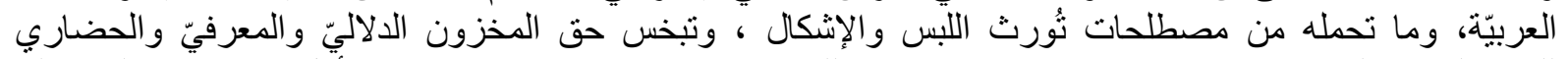

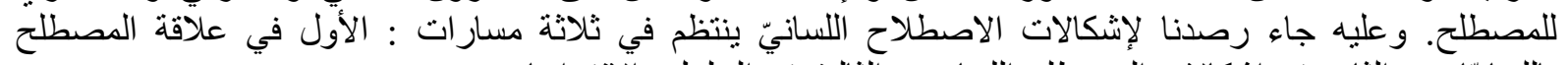

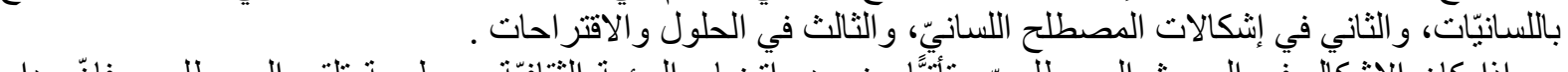

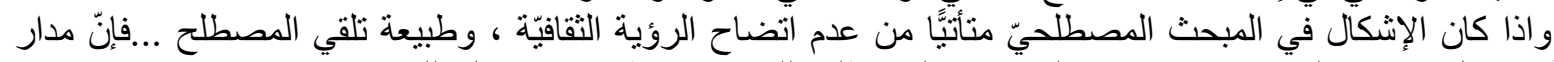

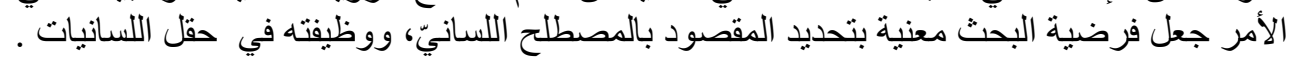

\section{• علاقة المصطلح باللسانيّات}

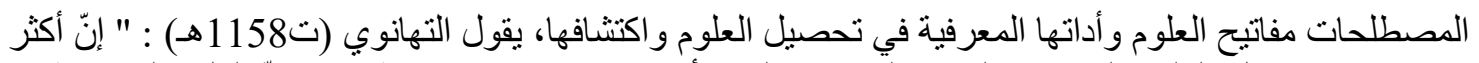

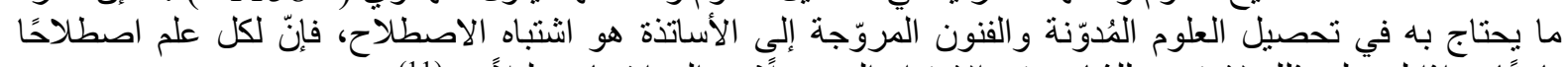

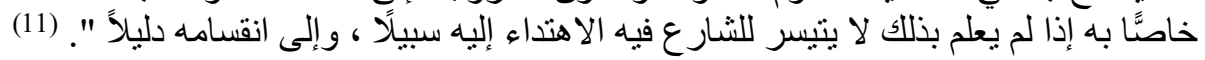

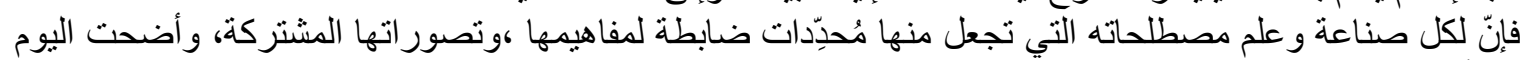

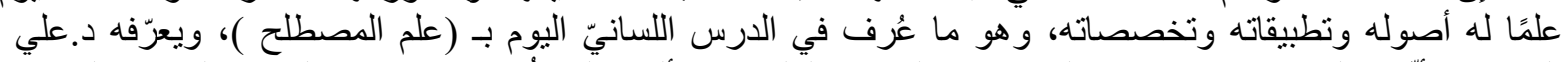

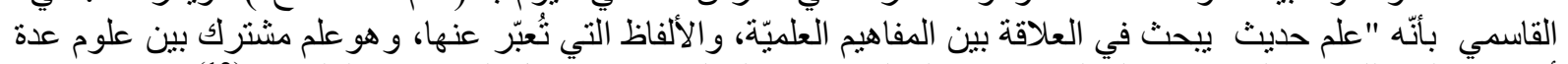

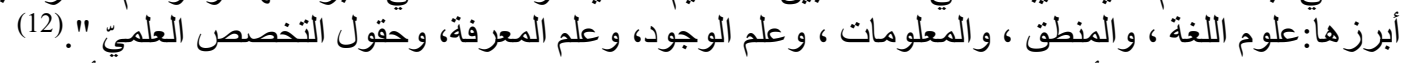

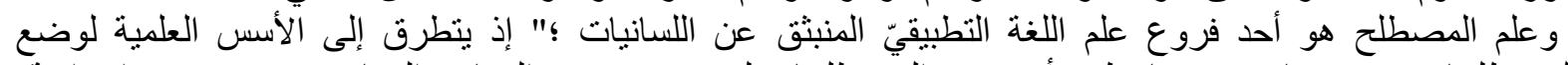

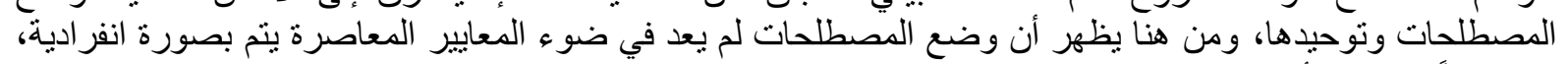

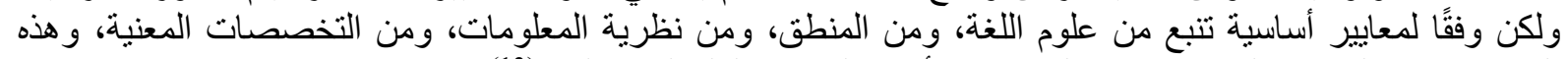

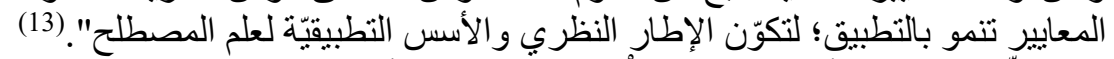

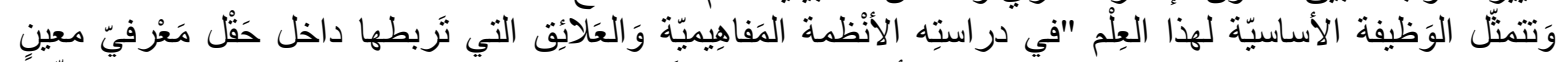

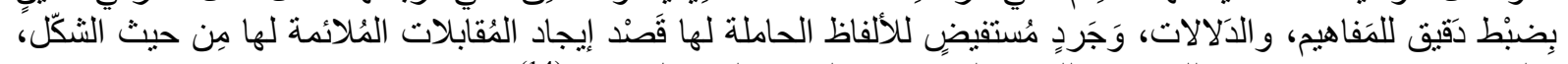

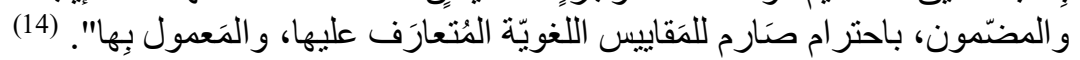

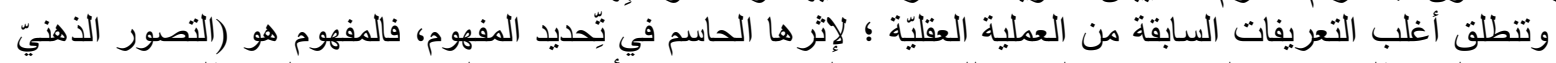

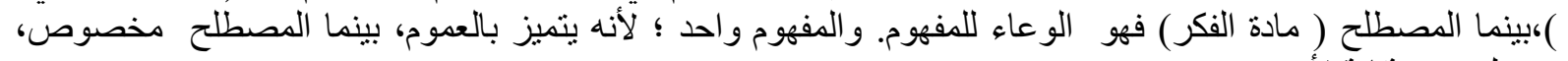
ويختلف من ثقافة لأخرى. والمصطلح في العُرف اللّغويّ: من الاصطلاح و هو :" العُرف الخاص،أي اتفاق طائفة مخصوصة من القوم على وضع

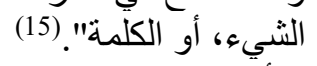

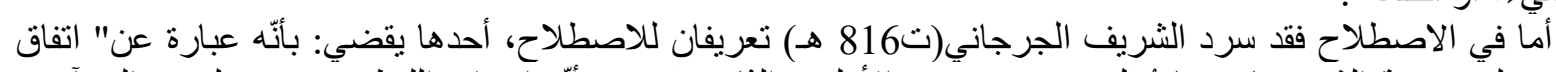

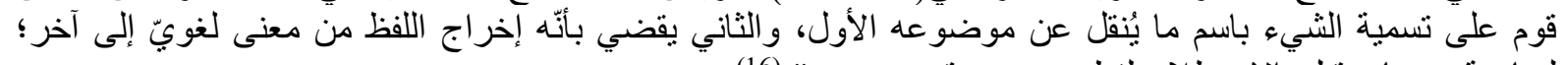

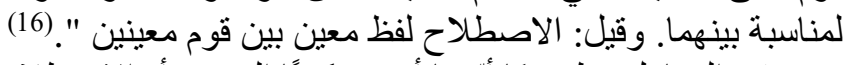

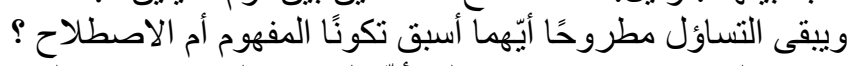

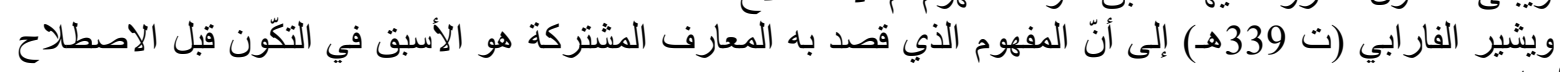
" و المعارف المشتر المثة في باديء رأي الجميع هي أسبق في الزمان من الصنائع العملية، ومن المعارف التي تخصّ صناعة (17) منها" 


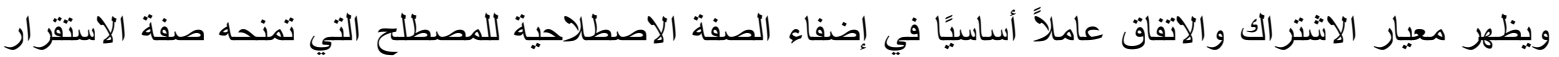

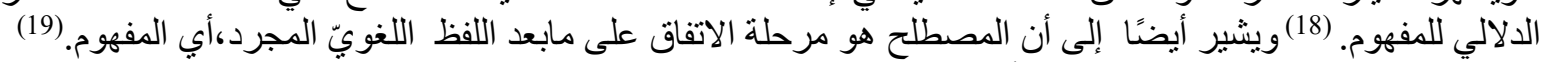

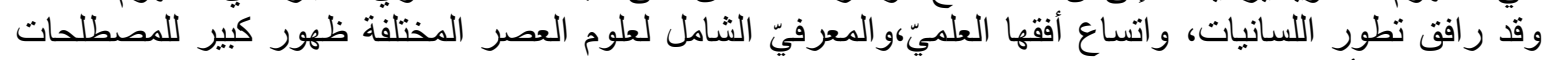

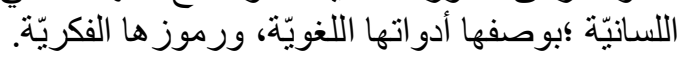

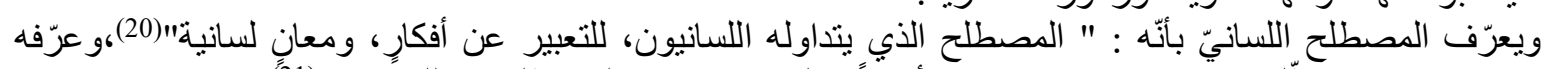

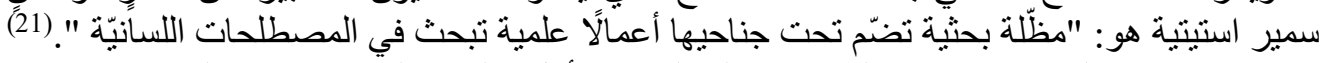

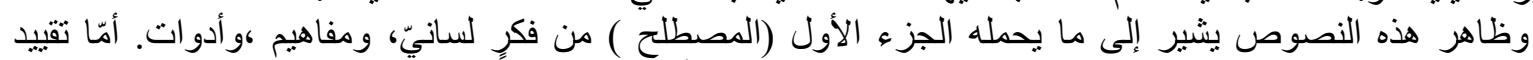

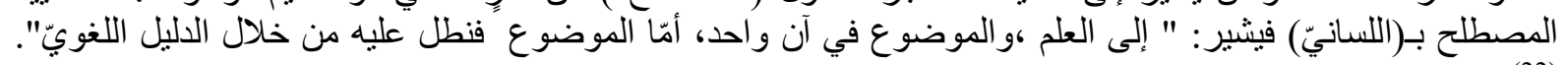

و هذا التقييد الاصطلاحي المرتبط بالعلم ،وموضوعه نابع من أصل الدراسة اللسانية،وهي الأم (اللسانيات) "التي

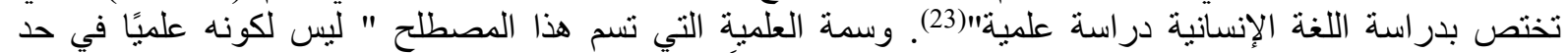

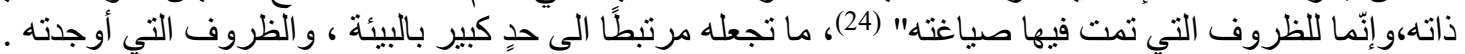

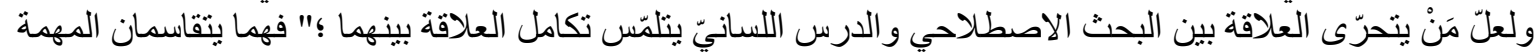

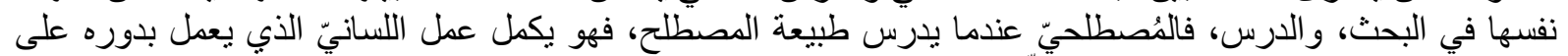

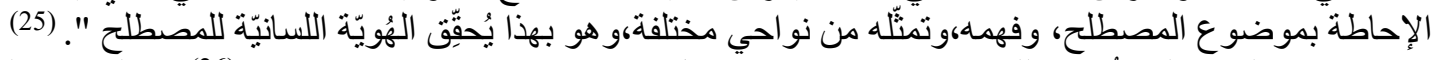

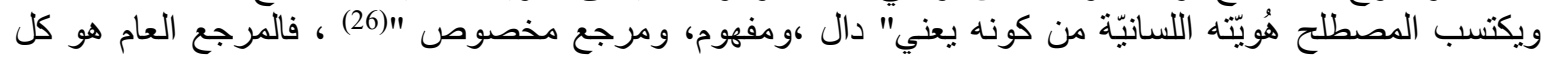

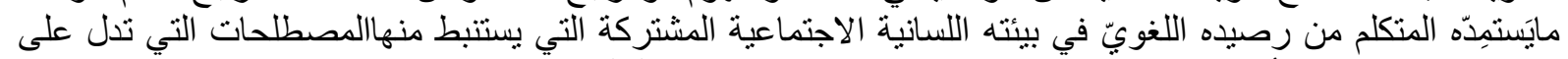

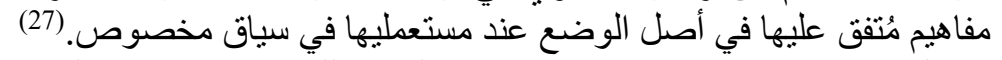

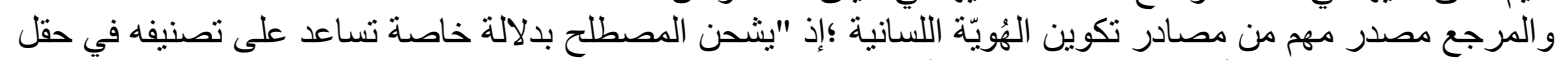

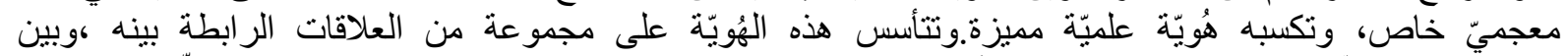

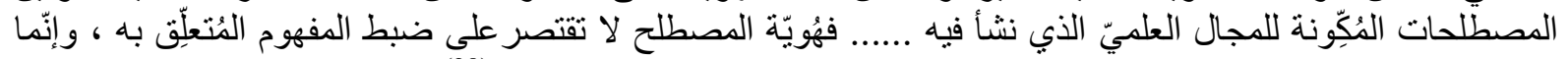

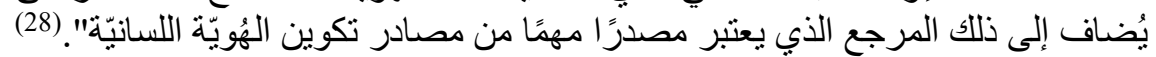

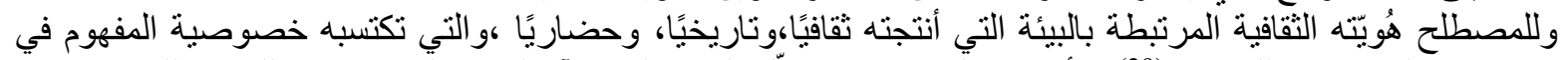

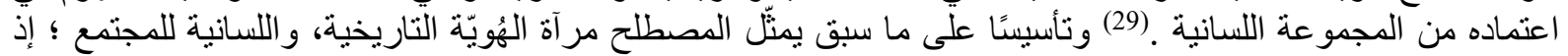
تعكس سيرورة المفهوم، و علاقته بمستعمل اللغة في محيطها مانسا الاجتماعي .

\section{• (أصناف المصطلح اللسانيّ :}

يميّز حسين نجاة بين ثلاثة أصناف للمصطلح اللسانيّ :

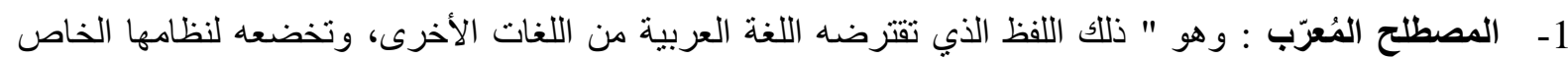

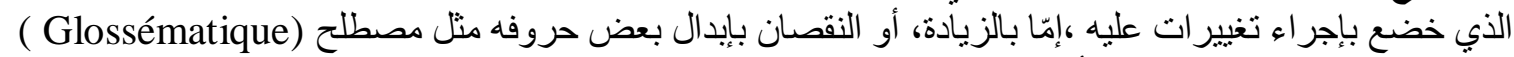

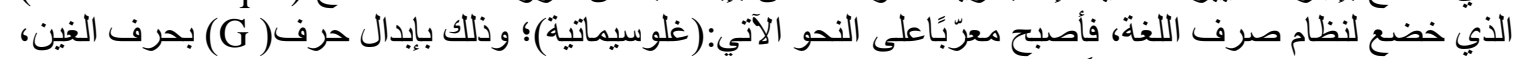

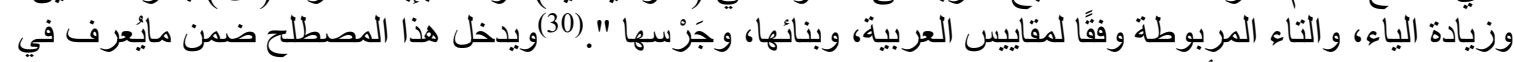

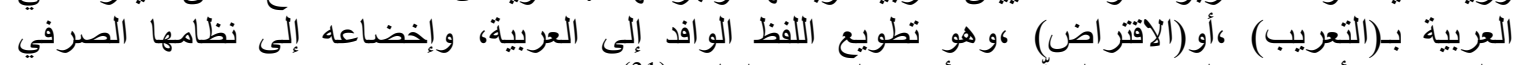

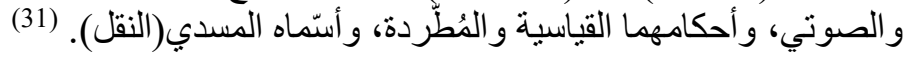

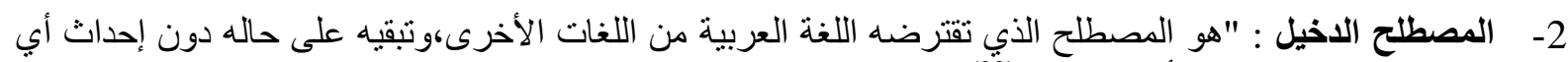

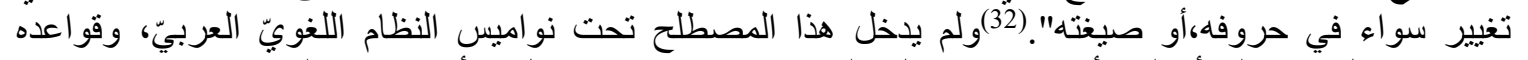

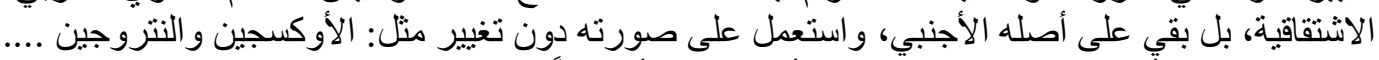

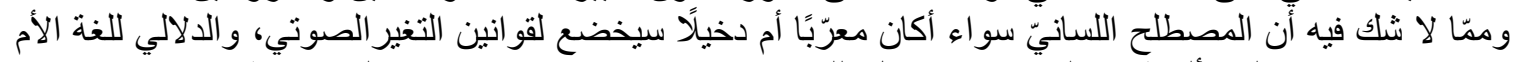

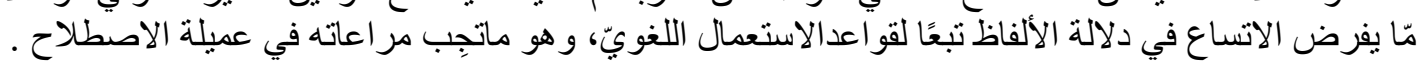

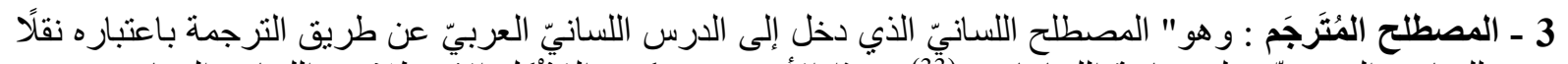

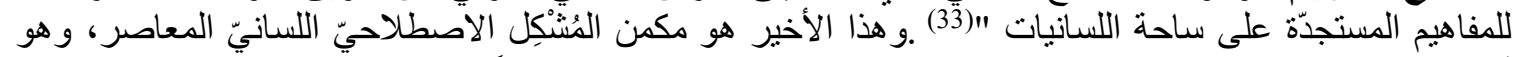

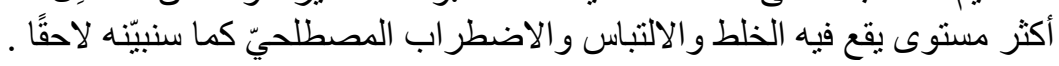




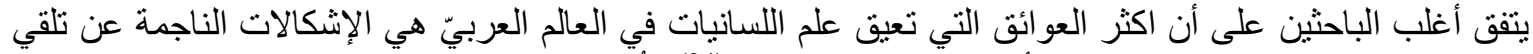

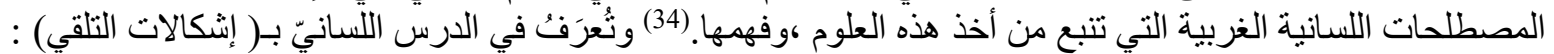

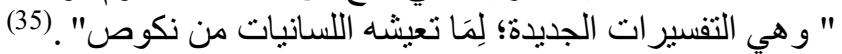

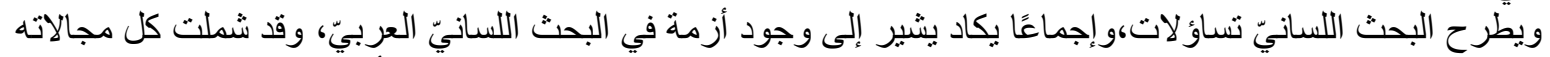

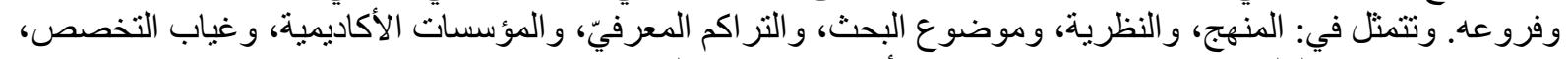

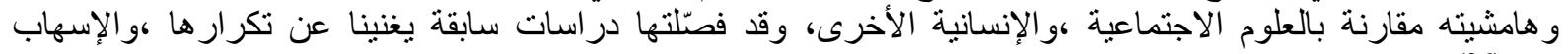
فيها. (36) و لا غرابة إذا ما قلنا أنّ أزمة المصطلح اللسانيّ قد شملت الدرس اللسانيّ بأكمله، "والأزمة عندنا أزمة انطلاق لا نمو "(37) نوان) ـ وبيان ذلك الخلاف في مدار انطلاق اللسانيات العربية الحديثة من التراث أم النظريات اللسانية الحديثة، وروافد المنهج

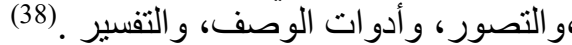

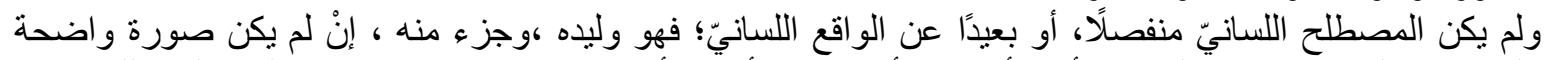

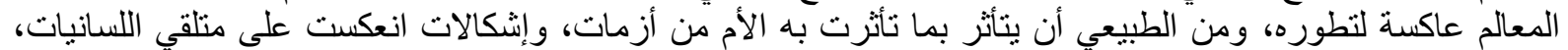

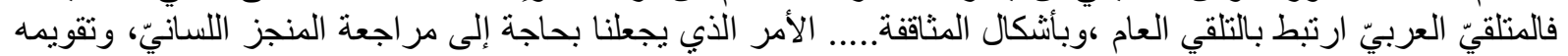

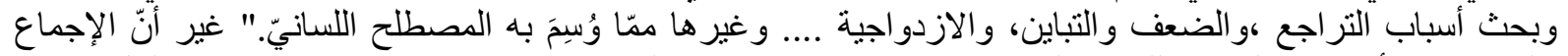

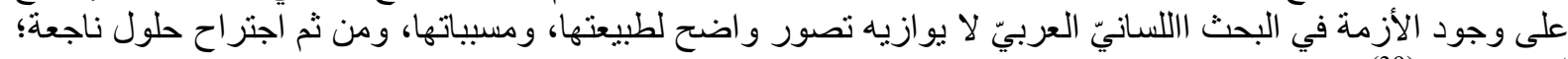

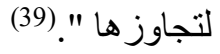

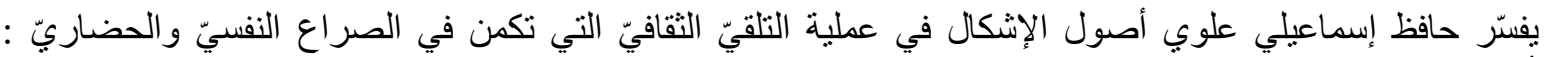

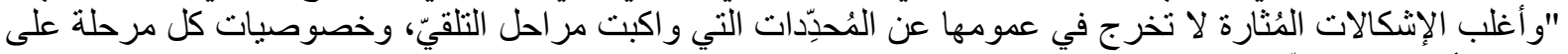

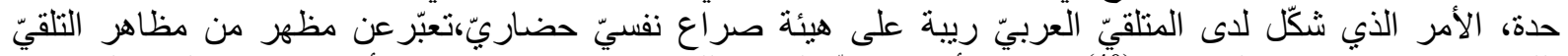

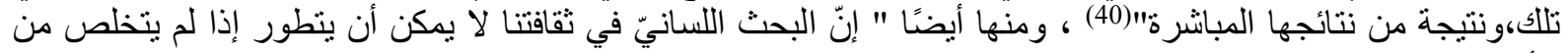

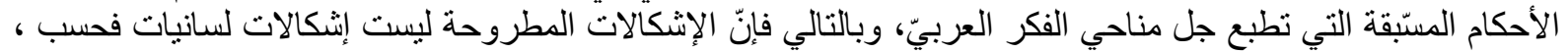

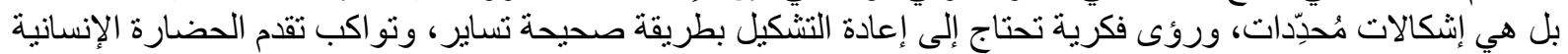
في مناحيها المتعددة". (41)

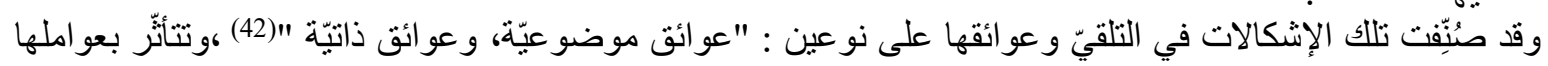

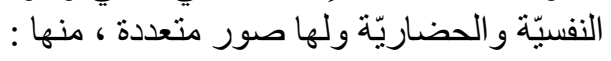

أ_صورة الغرب في المُتخيّل العربيّ :كأن تكون صورة مقولبة ،أو على هيئة الافتر اض، واضئ والحكم المسبق.

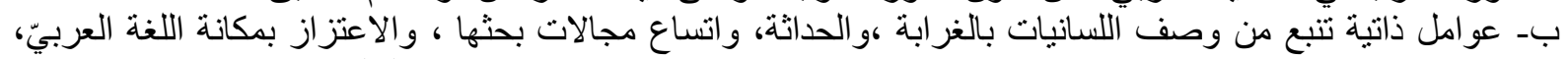

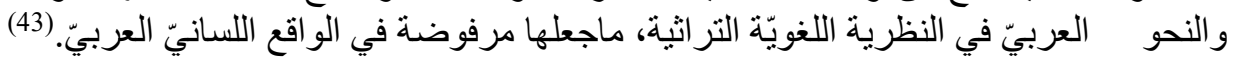

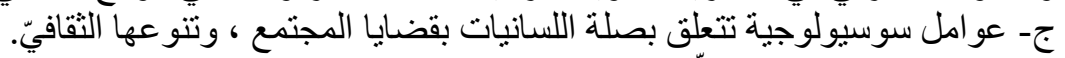

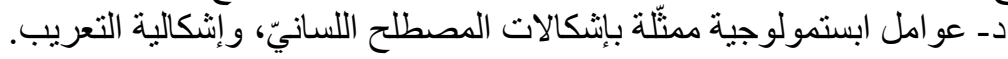

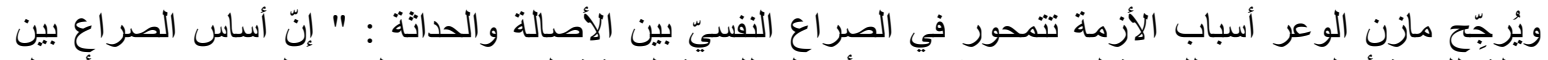

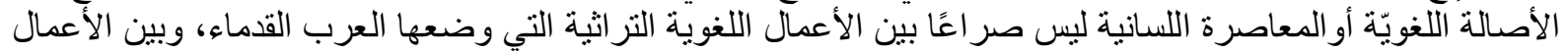

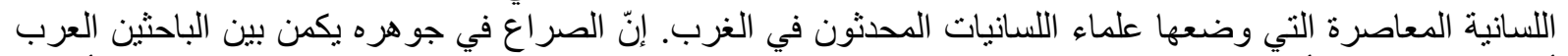

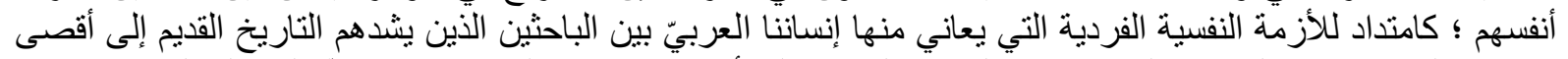

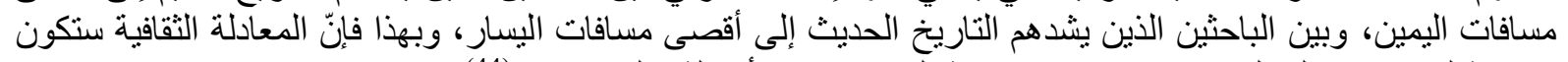

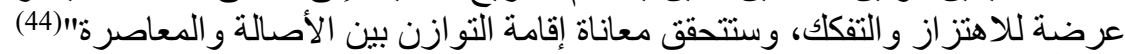

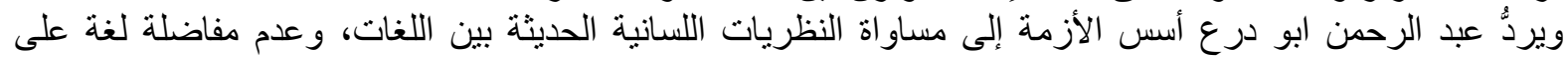

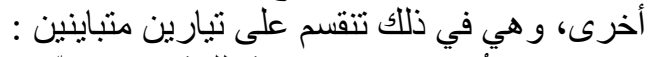

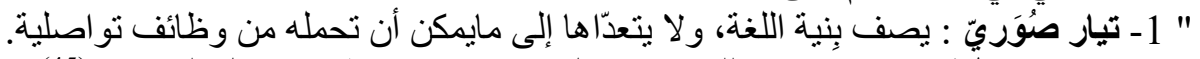

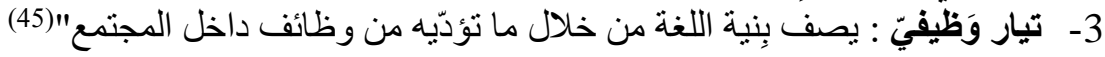

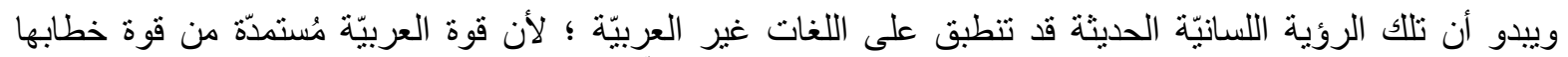

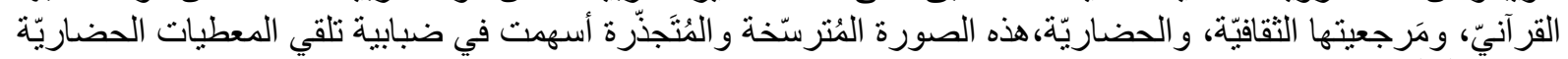




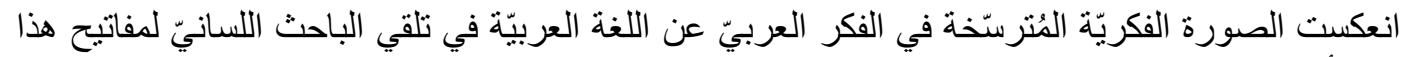

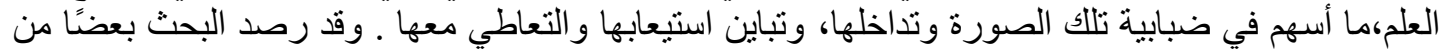

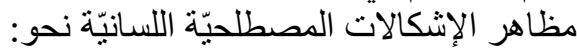

1- التذاخل الاصطلاحيّ بين المصطلح اللسانيّ، ومفهومه : (التعدد والاضطراب )

تقف في مقدمة إثكالات الدرس اللسانيّ المعاصر( الاضطر اب المصطلحيّ) في مركزية هذا العلم، وهو مرتبط

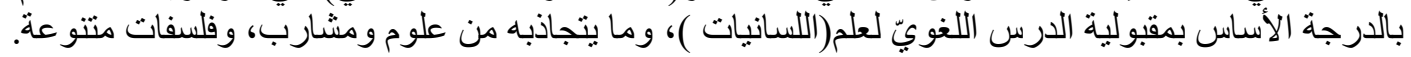

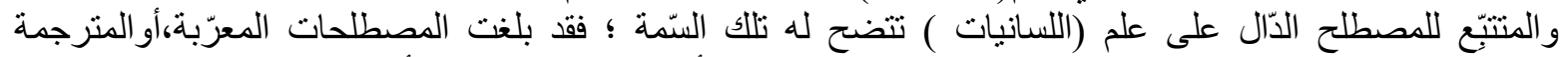

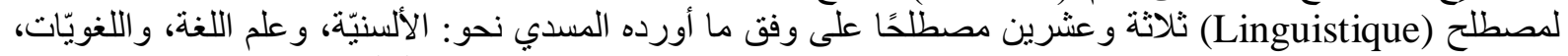

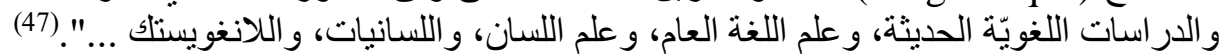

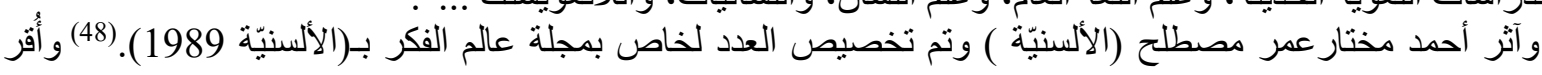

( الألسنيّة) في سوريا ولبنان ،و(اللسانيات) في تونس و المغرب العربيّ، لعلى حين تذبذب المصطلح في المشرق العربيّ

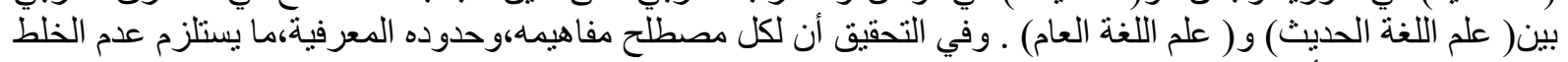

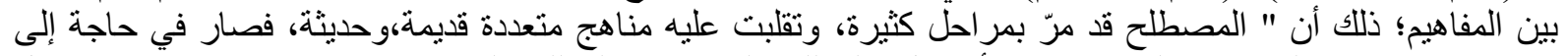

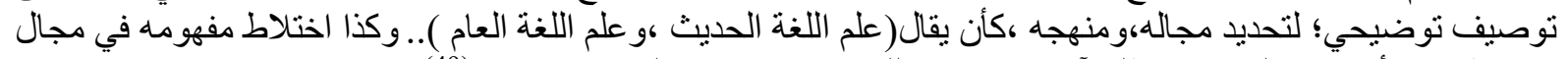

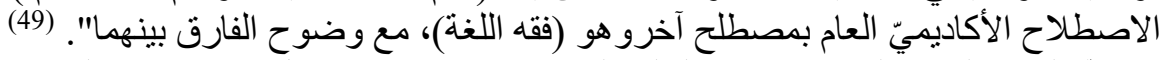

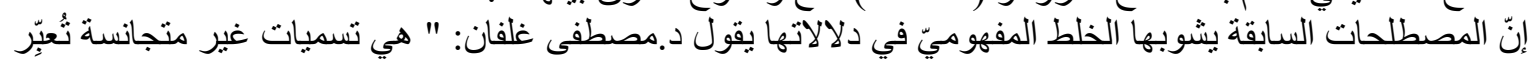

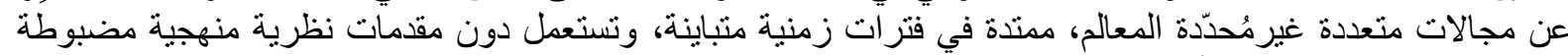

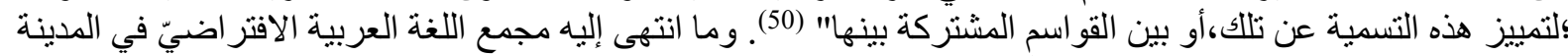

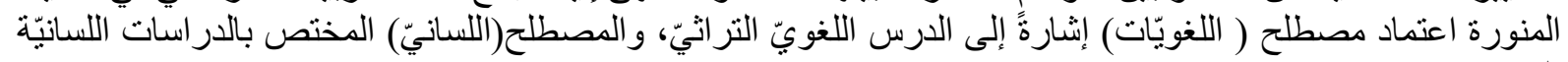

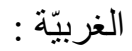

1- "مصطلح اللغويّات : يشير إلى المعنى الثامل،و الأصل الجامع للعلوم اللغويّة للغة العرب، (النحو، و الصرف ،وفقه اللغة، و المعاجم ).

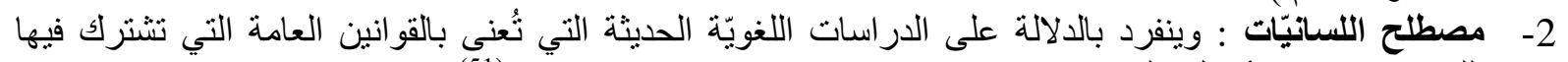

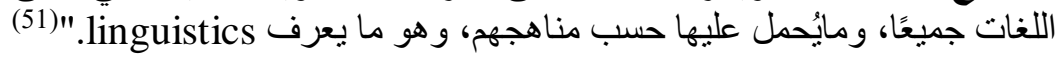

ولعلّ الإشكال الأكبر في تلقي هذه المصطلحات التي تباينت مفاهيمها بين القديم والحديث يعود إلى الاعتقاد الراسخ في " الثقافة اللغويّة العربيّة الحديثة (اللسانيّات) ليست استمر ارًا للبحث اللغويّ العربيّ القديم ،بل وردت إلينا نتيجة الانفتاح

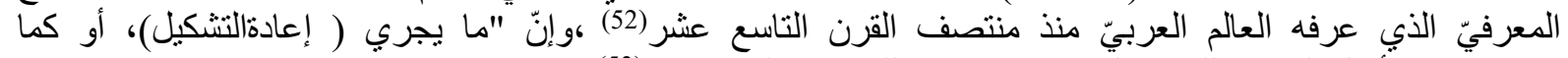

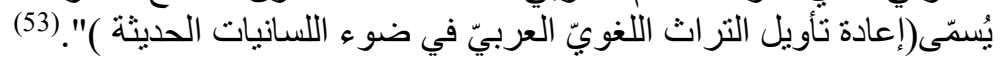

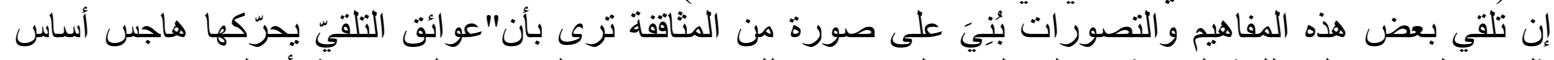

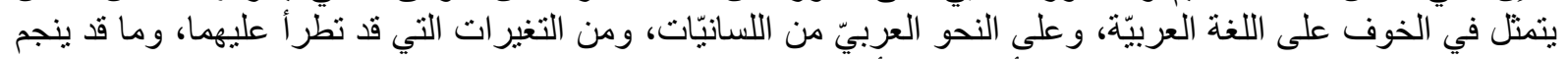

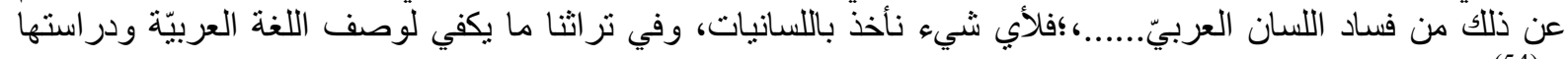
(54)."

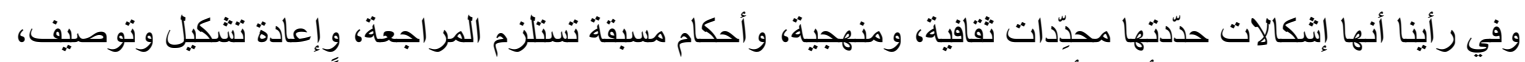

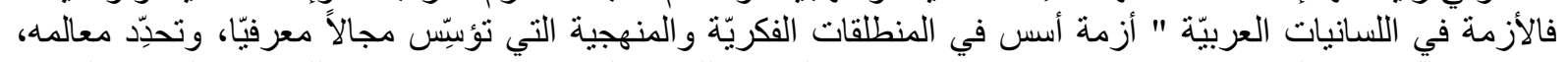

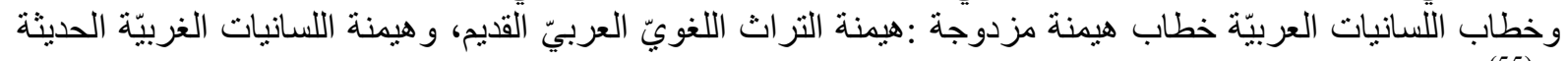
(55)."

ولم يقتصر التعددالمصطلحيّ، والاضطر اب المفهوميّ على اللسانيات، بل امتد إلى نظرياتها، ومجالاتها، من ذلك :

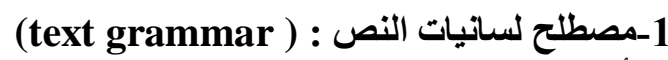

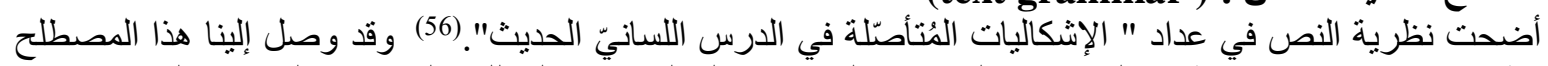

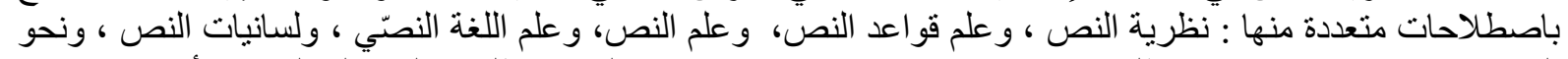
النص . "ويستخدم هارفج مصطلح ( textologie ) ،بينما يستخدم دريسلر مصطلح (علم دلالة النص)، أمّا(سوينسكي) 
فيشير إلى مصطلح نحو النص، وتداولية النص، و وعلم لغة النص، ونظة ونظرية النص ". (57) ، وليس المقام ههنا مقام إحصاء

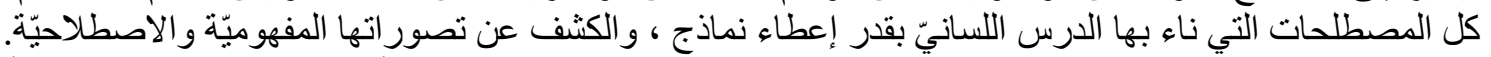

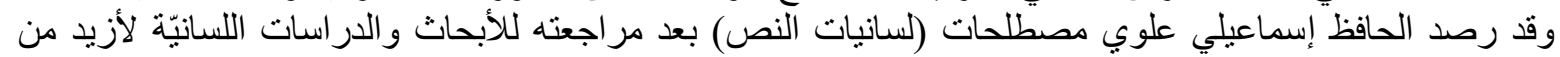

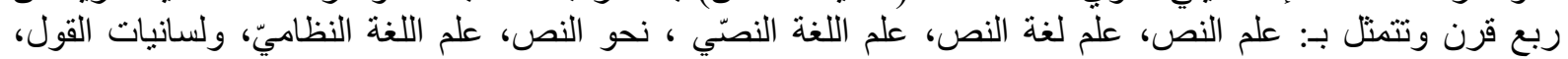
وتحليل الخطاب. (58)

و لا تخرج إنشالات هذه النظرية عما يأتي :

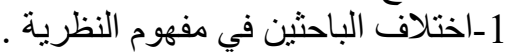

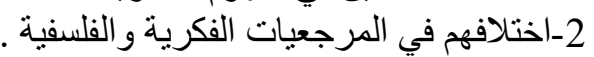

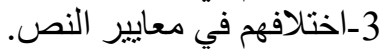

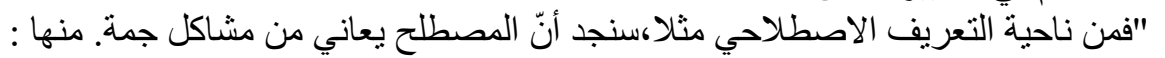

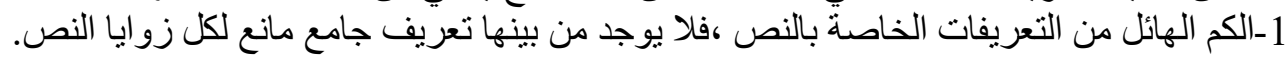

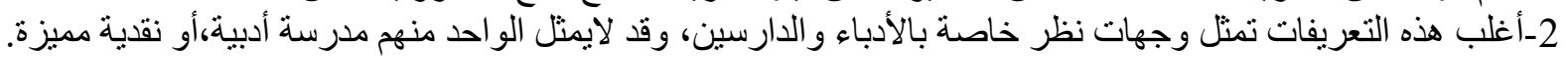

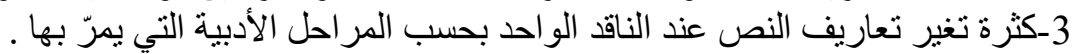

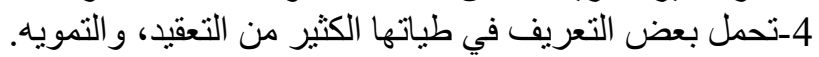

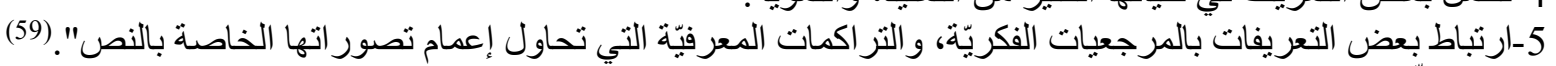

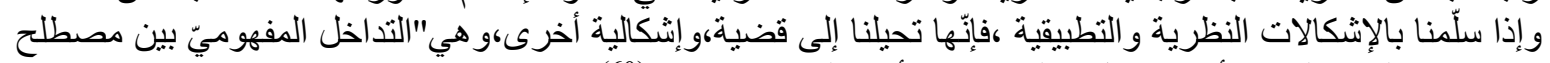
النص، ومصطلحات لسانية أخرى منل ( الخطاب، الأثر ، التناص .....)".".

\section{2-ترجمة المصطلح اللسانيّ :}

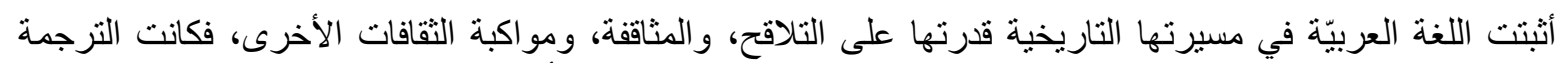

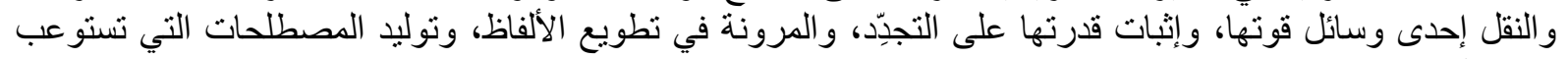

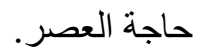
وتمثل الترجمة العقبة الكأداء في الدرس اللسانيّ المعاصر، وتحمل التحل الكثير من التساؤلات، منها:

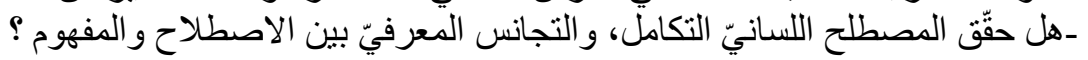

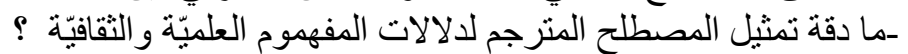

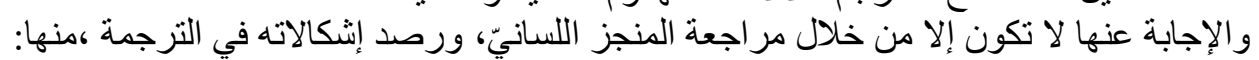

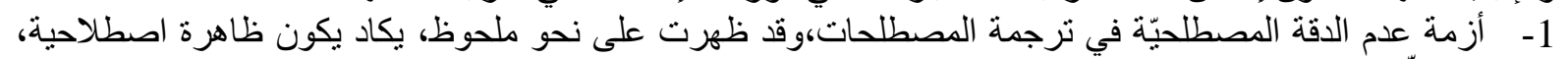

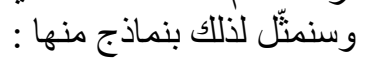

\section{1- (مصطلح التداوليّة (Pargmatique)}

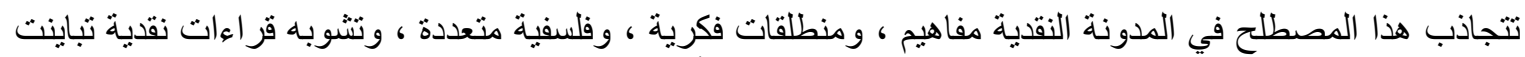

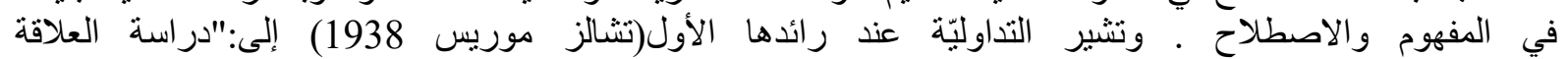

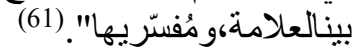

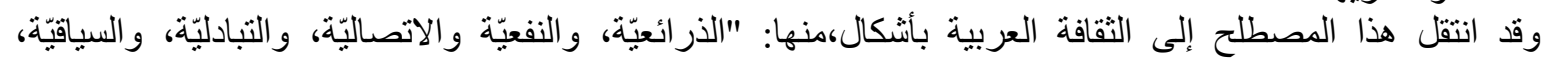

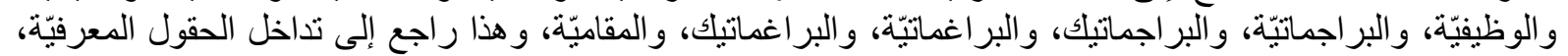

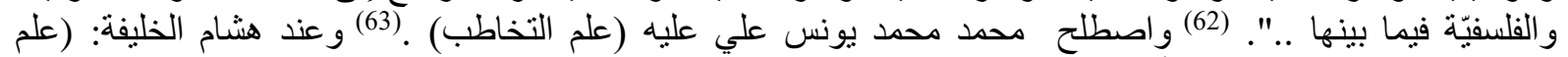

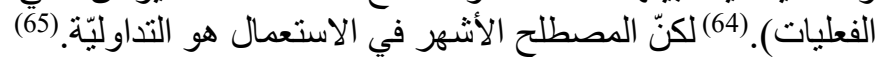

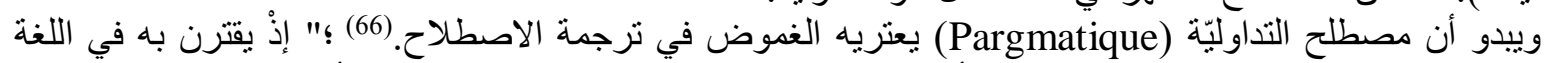

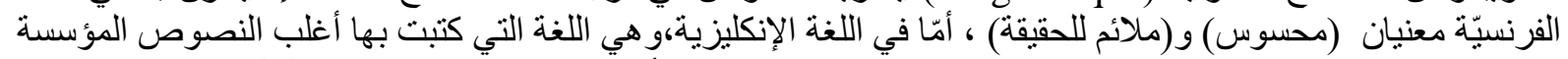

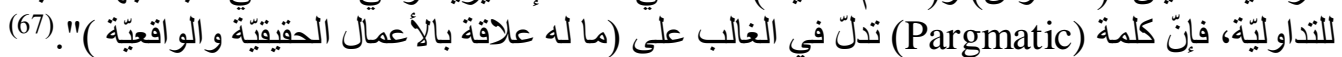

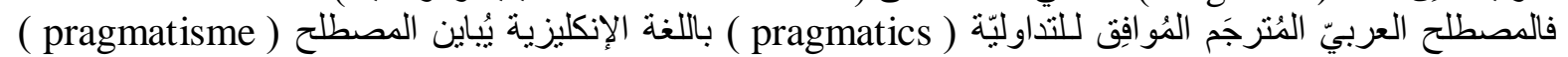

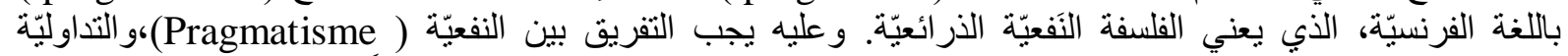

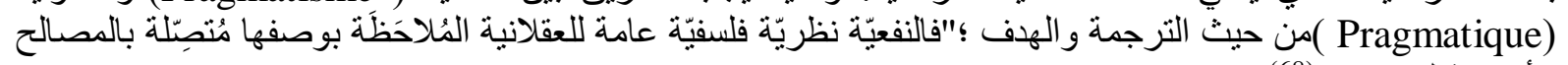
الأساسية للإنسان". (68)

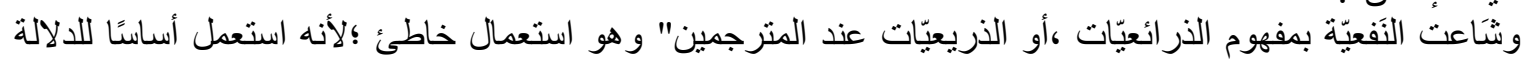

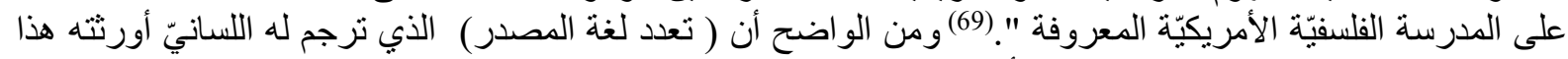

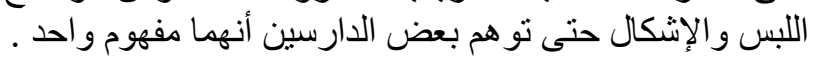


ومن التساؤلات المثبرة للجدل و النقاش أن الدرس اللغويّ العربيّ إلى عقد السبيعنات من القرن المنصرم تعلوه سمة (الثبات

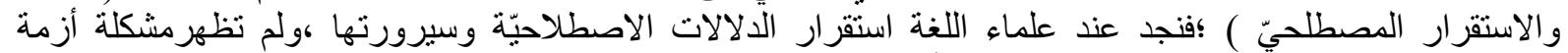

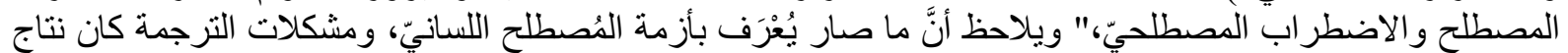

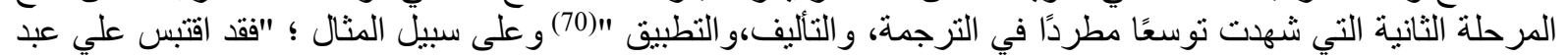

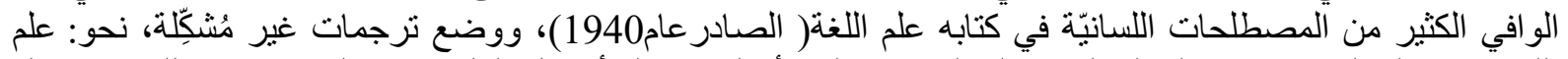

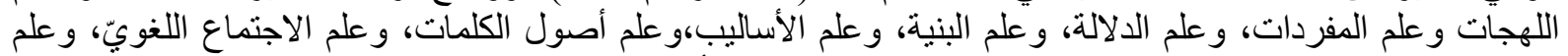

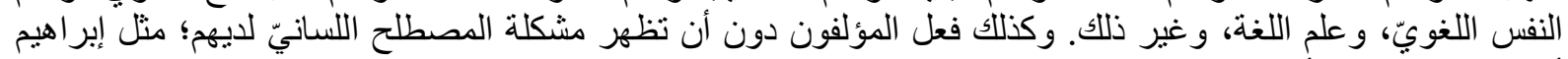

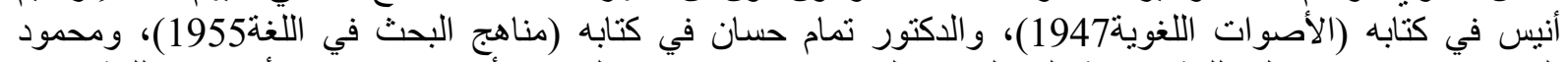

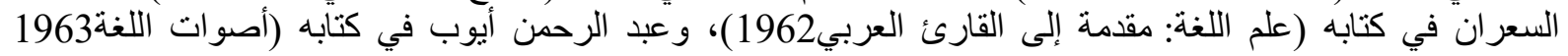

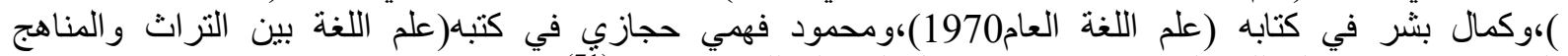

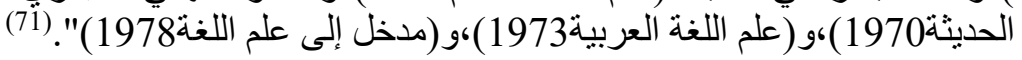

\section{2-مصطلحا التماسك Cohesion) ) و والانسجام ( coherence )}

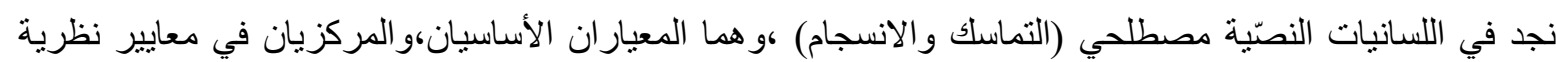

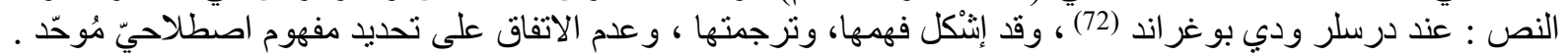

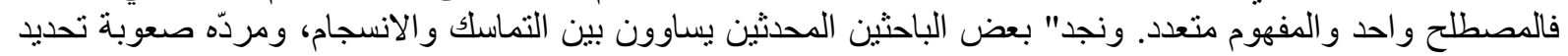

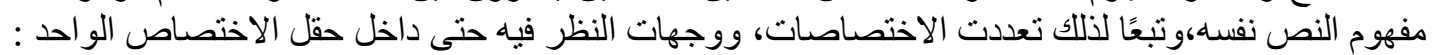

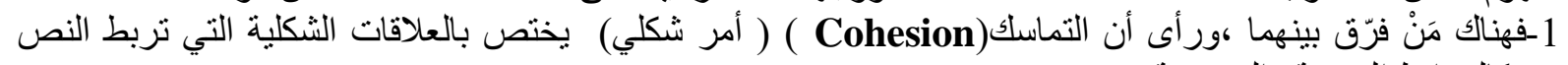
كالروابط النحوية و المعجمية .

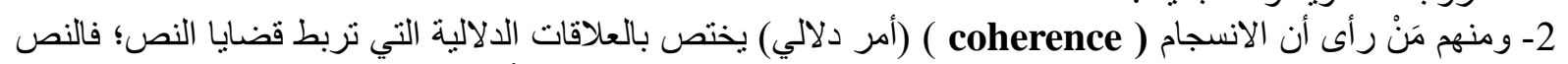

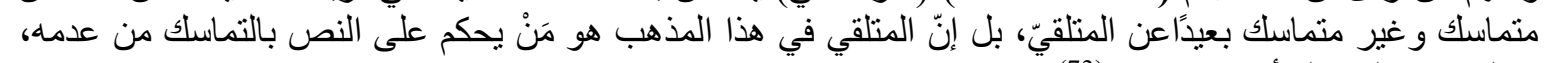

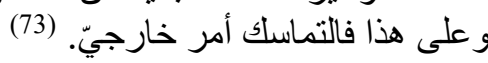

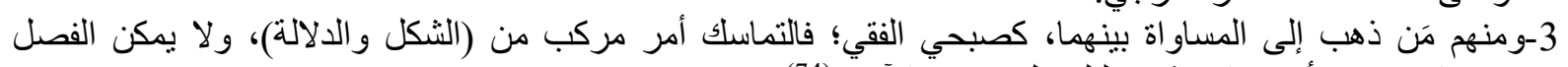

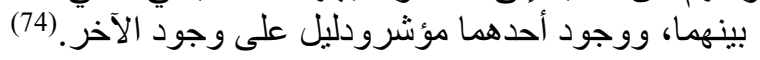

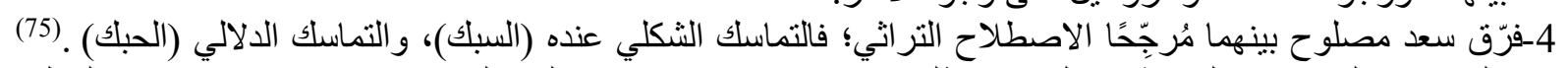

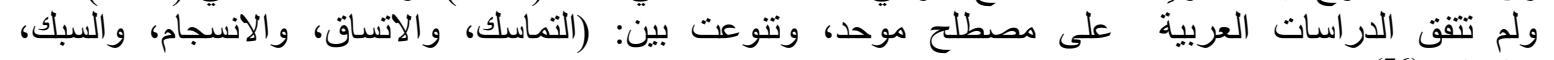

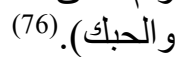
وترد أسباب هذا التذاخل المفهومي إلى الخلاف بين المعنى المعجمي للمصطلح الذي يترجم له الهن المترجم المساوي

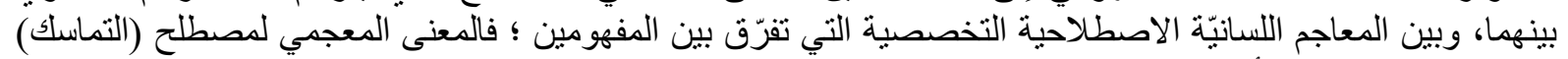

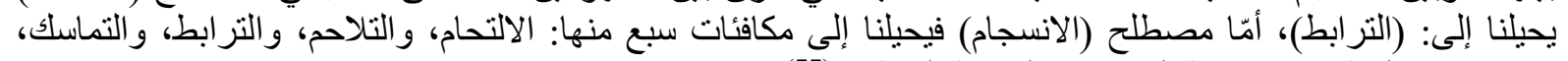

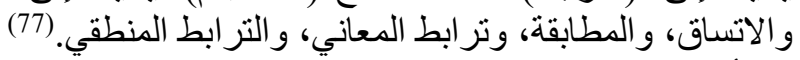

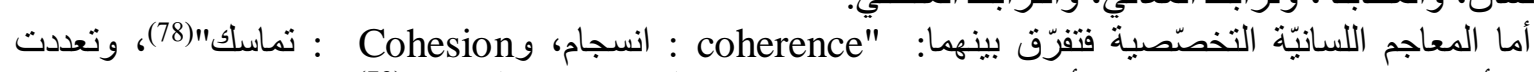

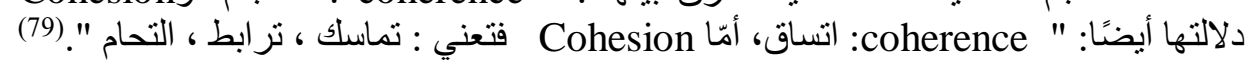

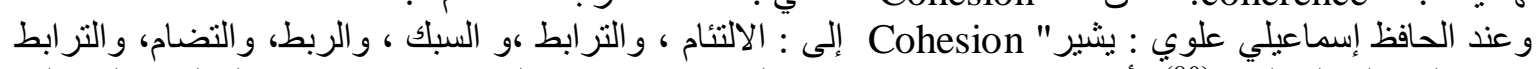

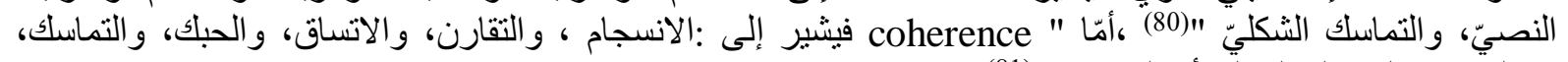

والالتحام، والتماسك الدالآلي أو المعنوي". (81)

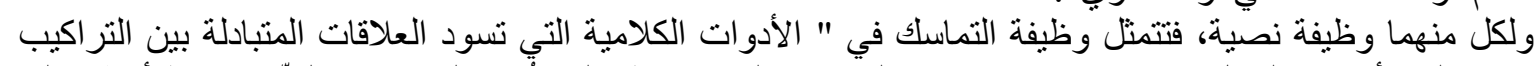

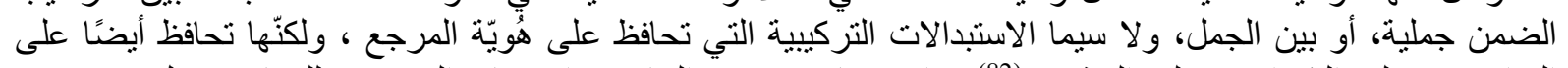

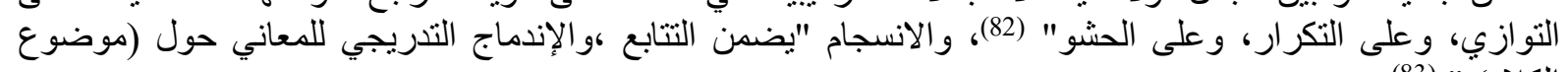

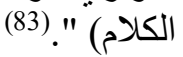
إن تداخل المفاهيم يكاد يرسم للقارئ ،و الباحث اللسانيّ فوضى مصطلحية في نظرية علم النص.(84)

\section{2-ازدواجية المصطلح اللسانيّ :}

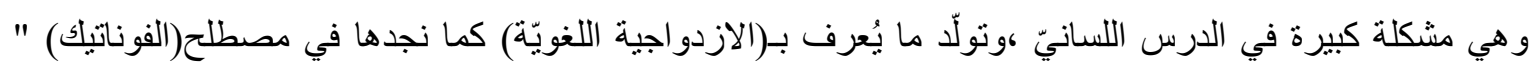

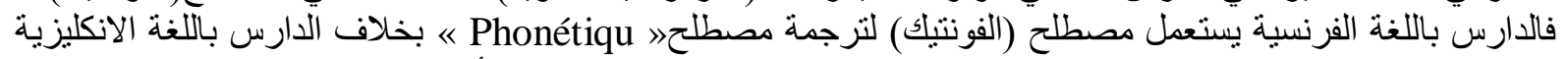

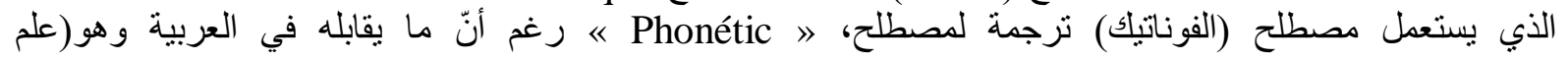




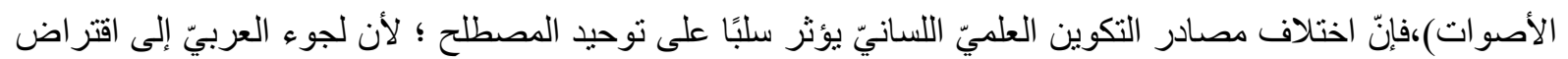

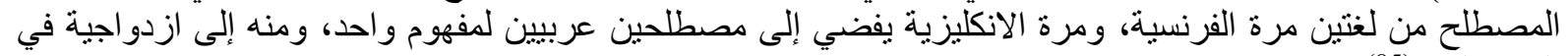

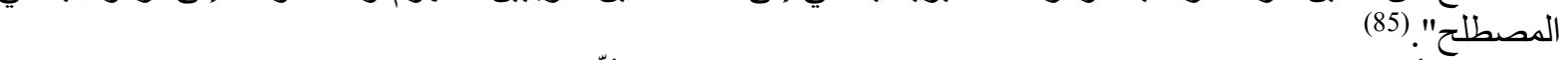

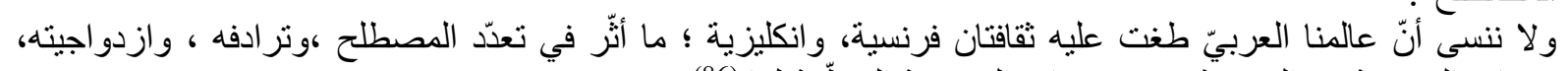

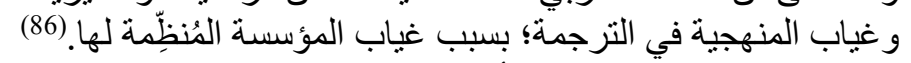

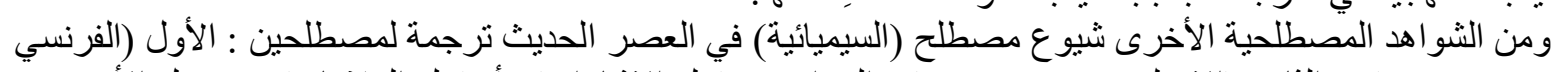

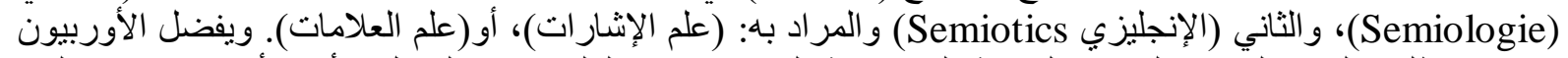

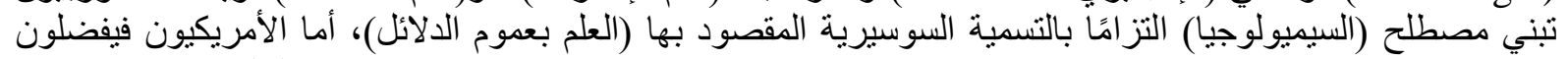

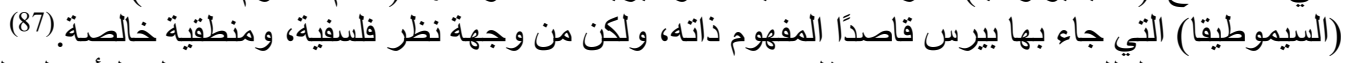

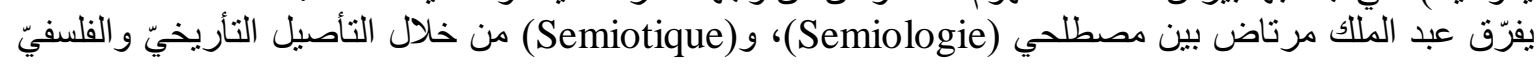
بقوله : بفرق " هما آتيان من الأصل الإغريقي المركب ( Semiolike)، وهو من بلورة شارل بيرس؛ فهو الذي كان يعدها بمثابة (العلم

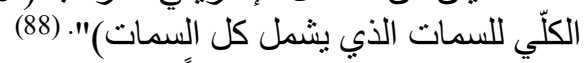

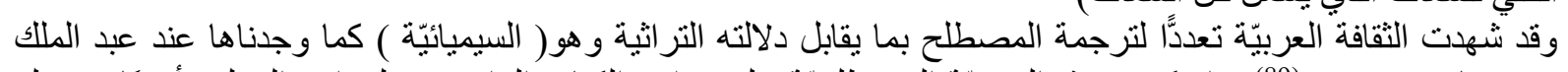

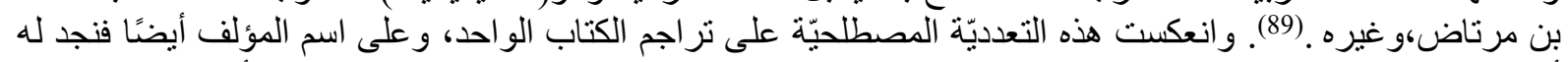

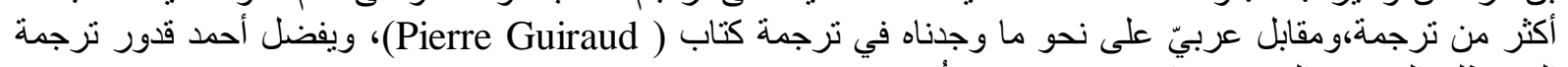

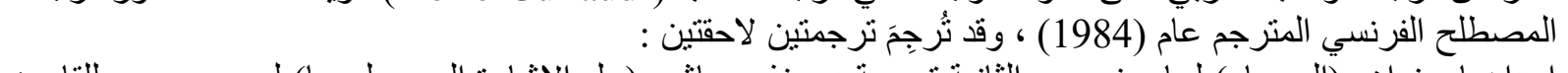

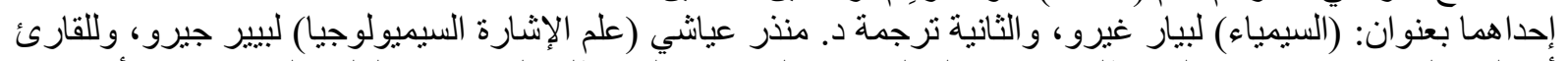

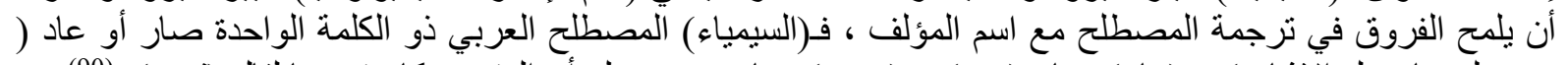

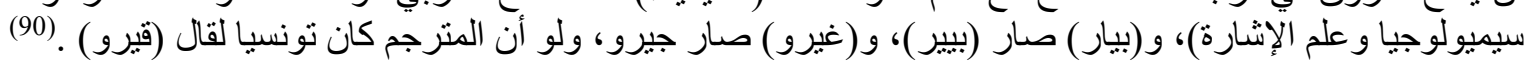

\section{3-صناعة المصطلح اللساني:}

وضع المجمعيون أسسا قديمة في صوغ المصطلحات ، وتوليد الألفاظ العربية، وتتميتها : " وهي الاشتقاق، والمجاز ،

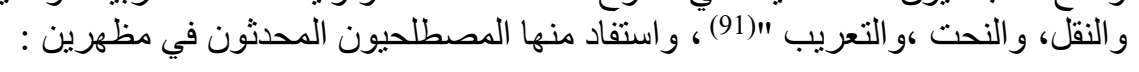

1- التوليد والنحت والاثتقاق : وقد واجهت هذا المظهر مشكلة عدم اتفاق المؤسسات العلمية المصطلحية، والتتسيق بينها

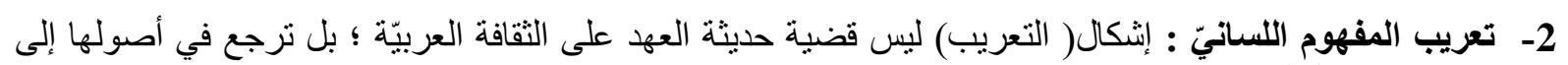

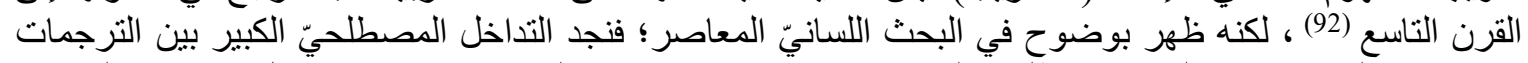

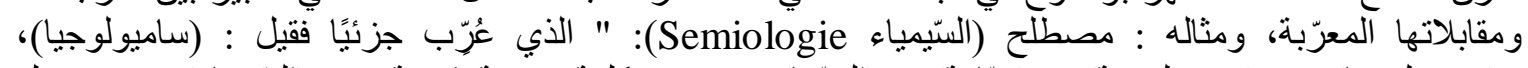

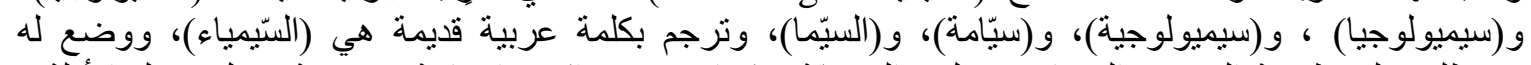

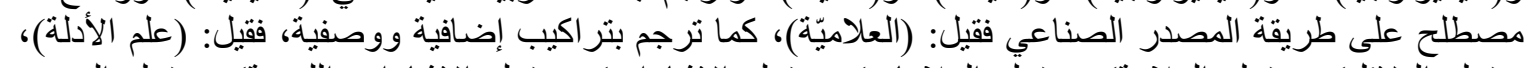

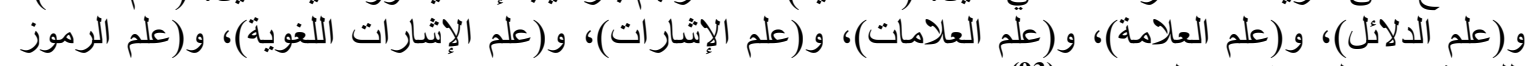

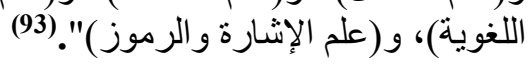

\section{-}

يقترح المسدي قانونًا في علم المصطلح، وهو وسيلة جديدة في صوغ المصطلح أسماه (قانون التجريدالاصطلاحي)

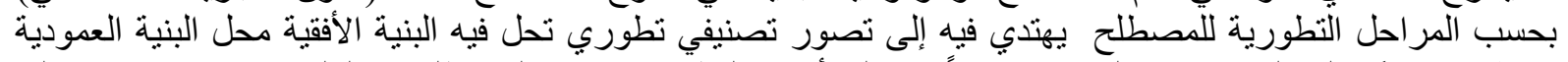

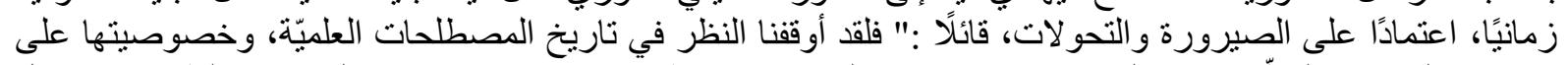

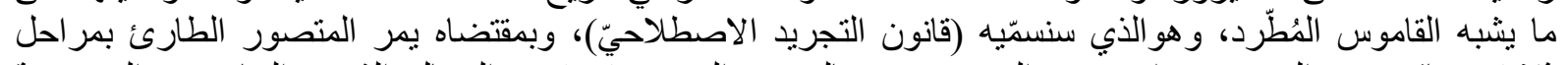

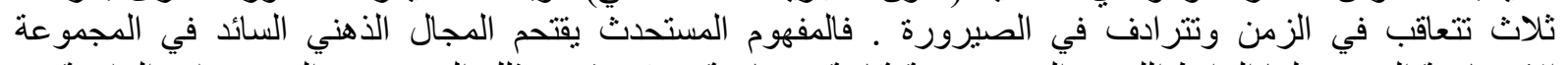

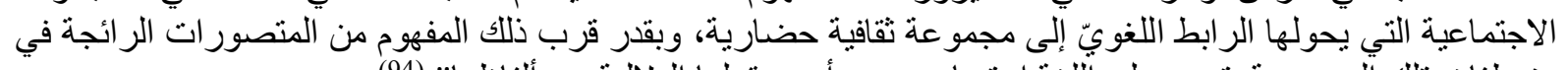

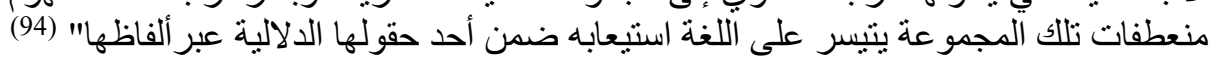

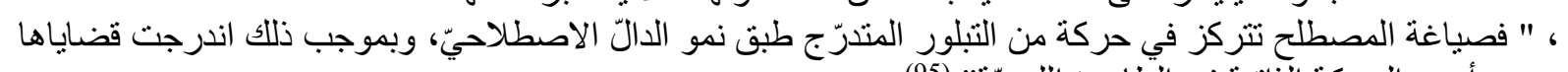

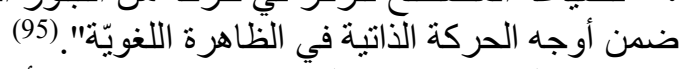

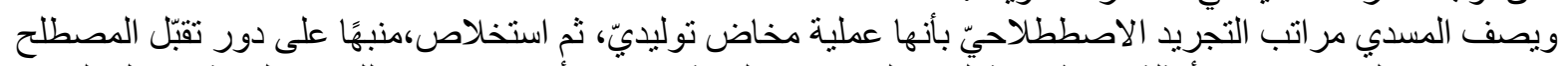

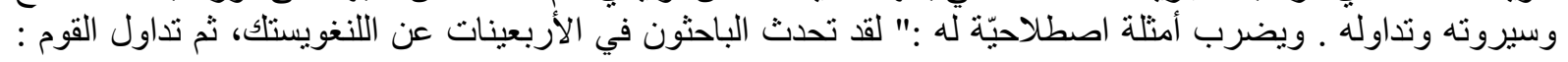




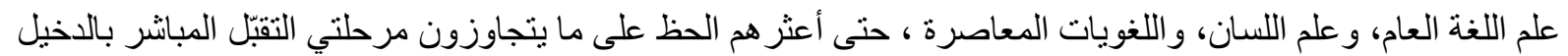

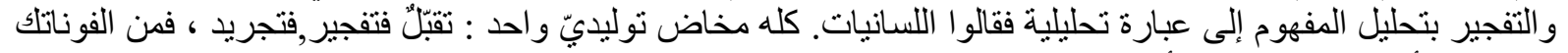

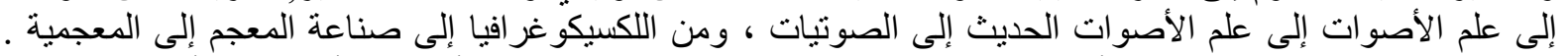

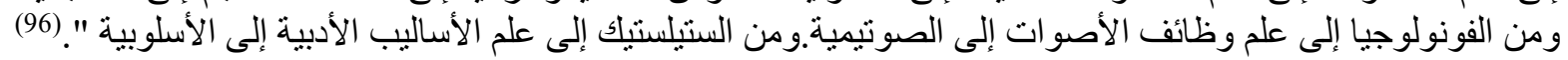

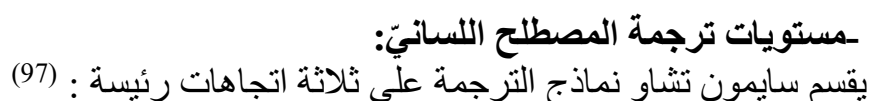

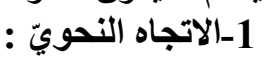

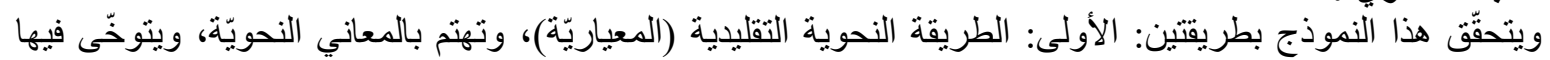

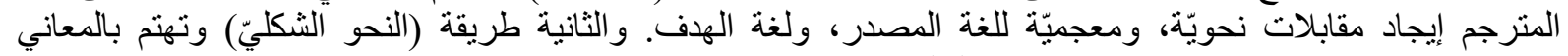

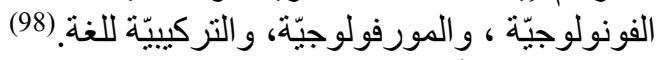

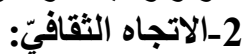

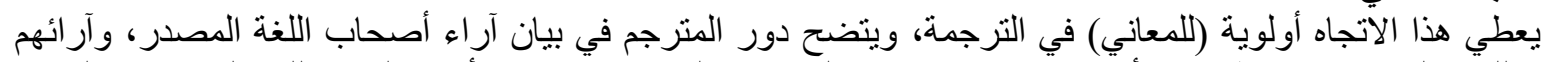

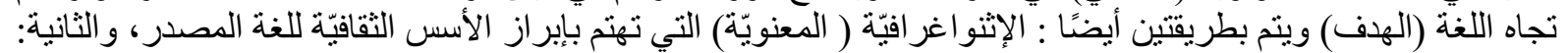

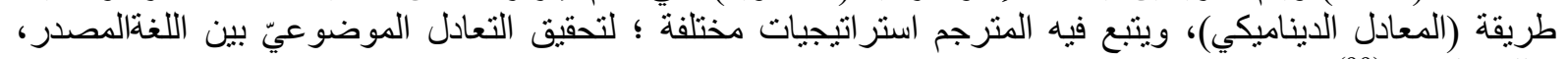
و اللغة الهدف. (99)

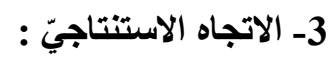

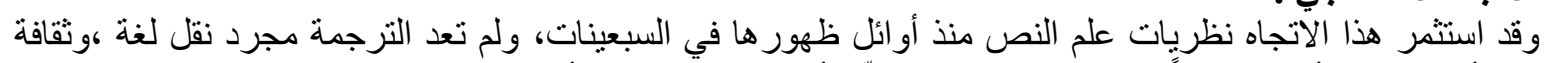

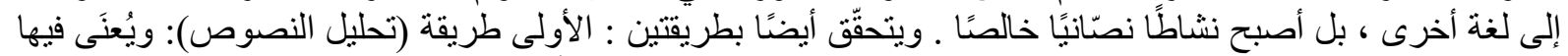

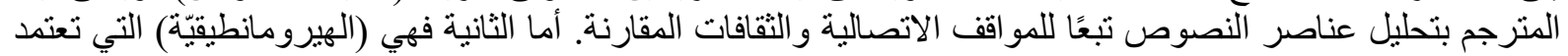

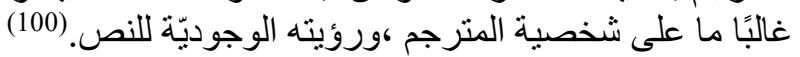

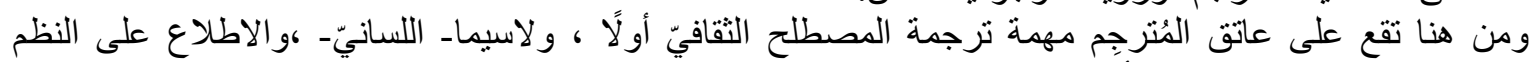

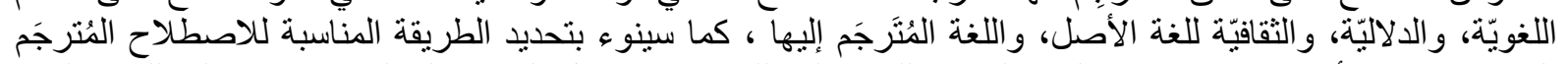

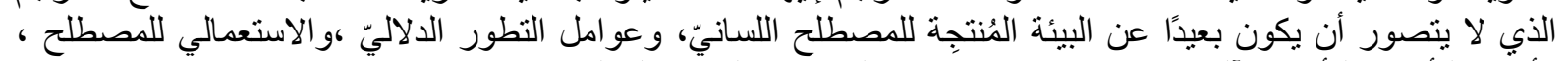

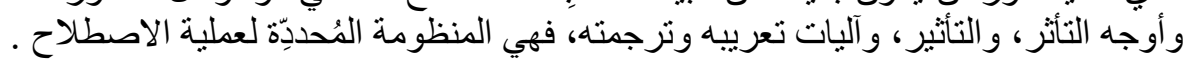

\section{م إثنكالات المصطلح اللسانيّ عوائق وحلول}

إثكالية التلقي متذبذبة بين الأصل اللساني، ومصادر التوطين، فكيف تتم المو اعمة والمواشجة بينهما؟ وما هو المستقبل

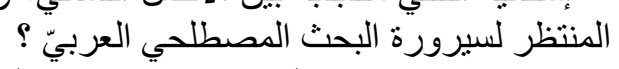

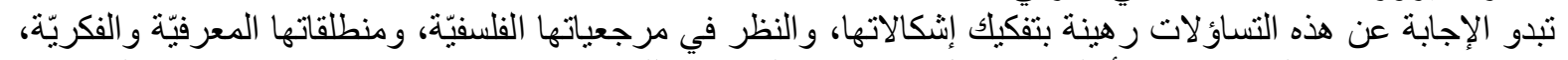

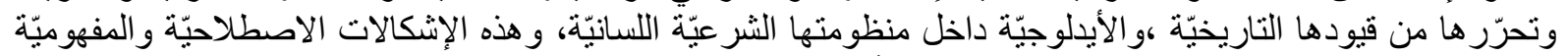

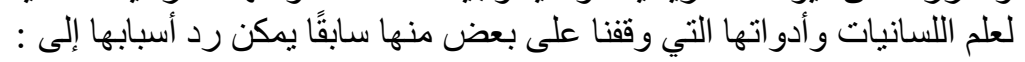

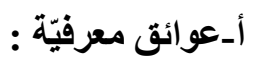

1- اتساع المجال المعرفيّ، والعلميّهو التخصنصي للسانيات ، وتعدّد وظائفها النصيّة، والاتصالية و التواصليّة ، وتنوّع

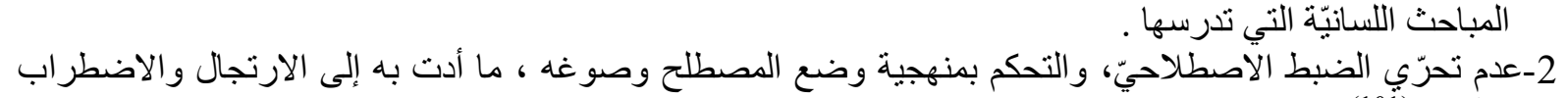

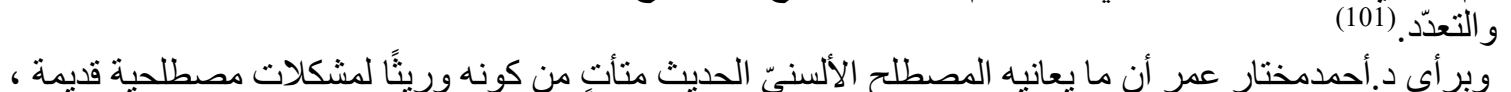

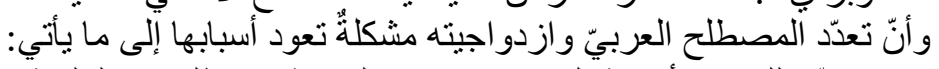

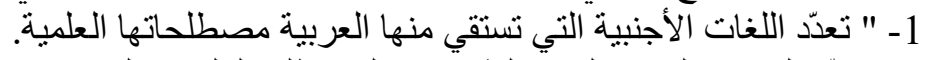

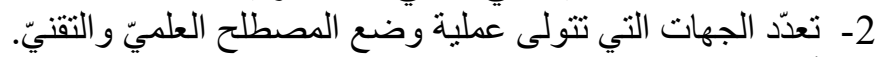

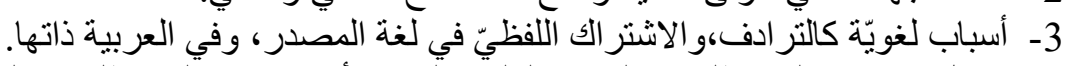

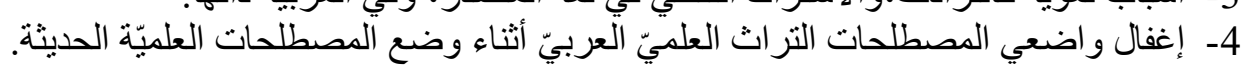

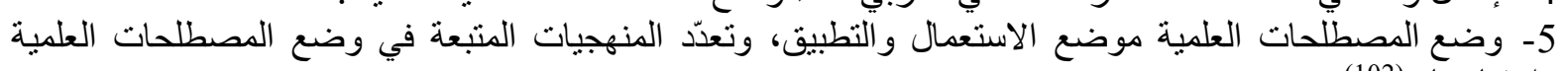
و اختيار ها". (102) 


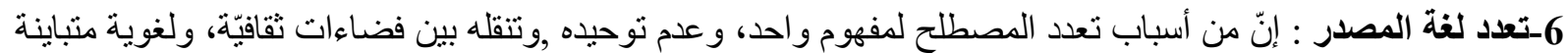

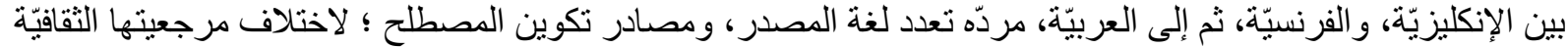

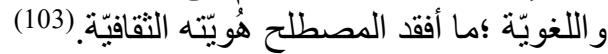

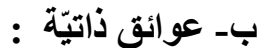
1ا-نباين التصور ذاتِّة : الرؤى اللسانيّة باختلاف مرجعيتها الثقافيّة ،و الفكريّة، والمعرفيّة ما أدى إلى ظهور مصطلحات تتسم

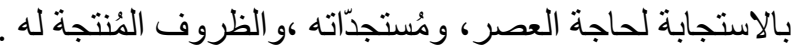

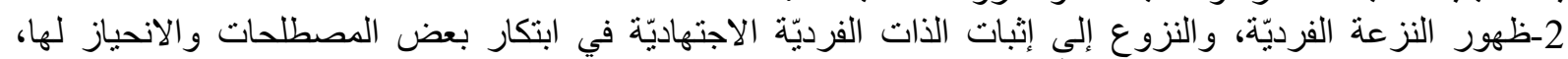
وتحولها إلى صورة من صور الإقليميّة أحيانًا .

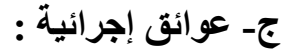

1- ضعف أداء المؤسسات المُختصّة بالحقل اللسانيّ ،سواء عن طريق الترجمة ، أو المجالات الأخرى في نوحيد

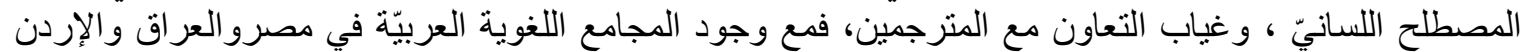

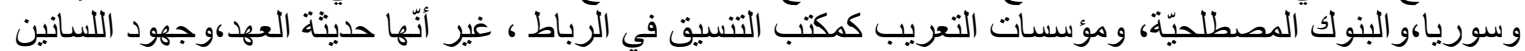

$$
\text { فيها بدت و اهية والبنو وضعيفة. }
$$

2-إصلاح العلاقة بين المفهوم و الاصطلاح ، ويذهب علدئ علوي إلى" أن المجامع التي أُسست في العالم العربي منذ القرن

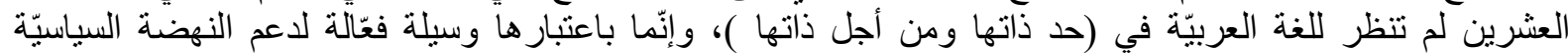

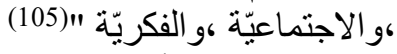

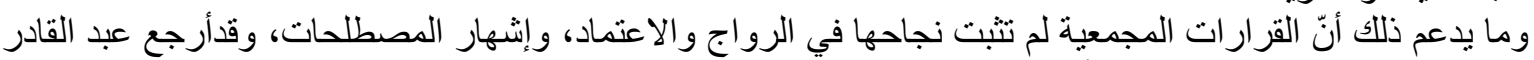

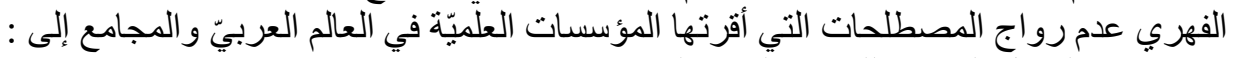
1 - 1 غياب التمثيل النظري للقضيّة المصطلحيّة.

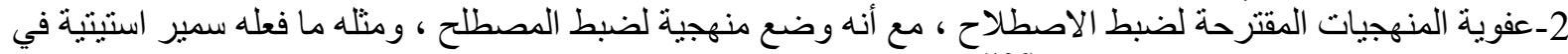

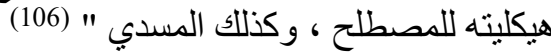

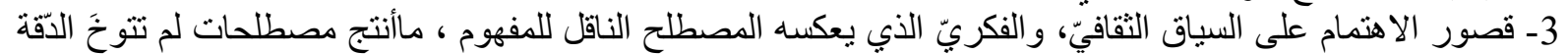

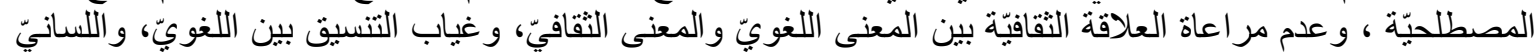

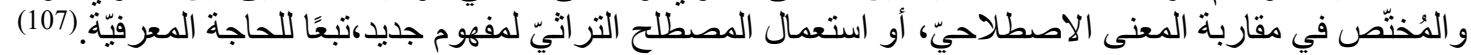

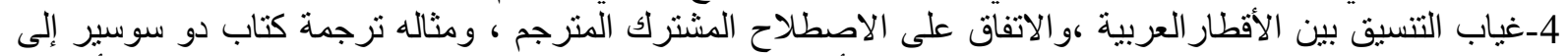

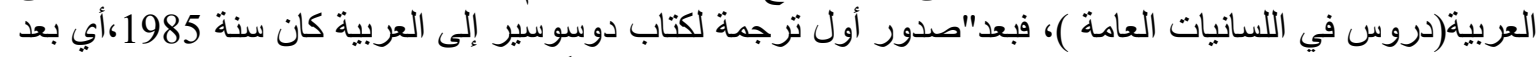

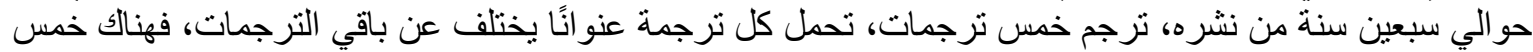

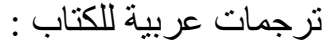

1-الترجمة التونسية /صالح القرمادية ومحمد عجينة ومحمد الثاوش ،الصادرة عن الدار العربية للكتاب، سنة 1985،

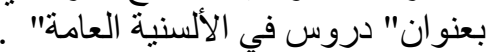
2-الترجمة السورية/يوسف غازية الإي ومجيد نصر،الصادرة عن دار نعمان للثقافة،سنة 1986، بعنوان" محاضرات في الألسنية العامة." 3-الترجمة المصرية/أحمد نعيم كر اعين،الصادرة عن دار المعرفة الجامعية بالاسكندرية ،والمنقولة عن الترجمة الانكليزية

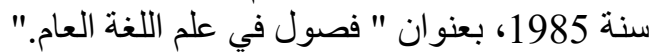

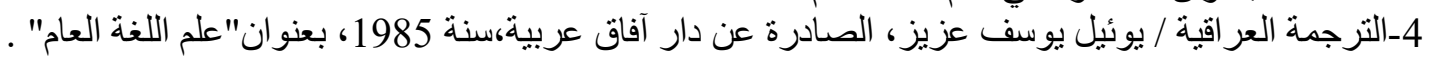

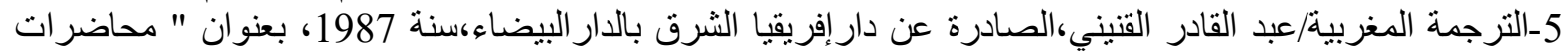

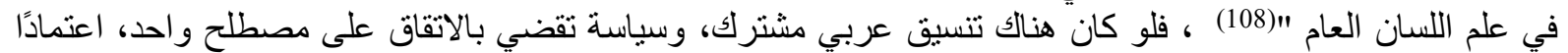

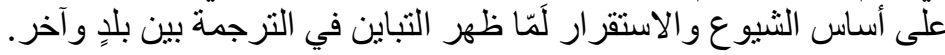

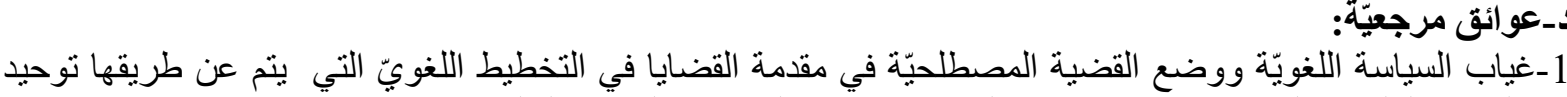
الجهود العلمية و النظريات الاصطية الصلاحيّة المبتكرة ، وتفي التعدديّة و التكرار السلبي.

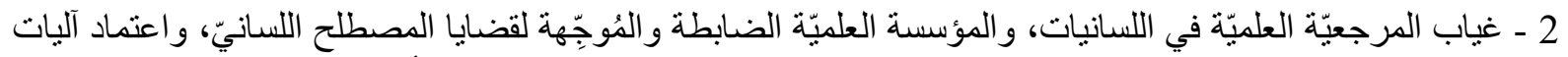

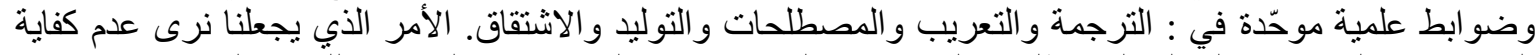

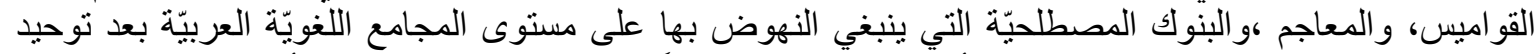

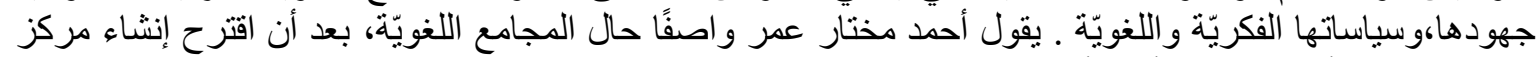

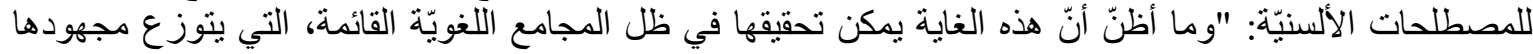




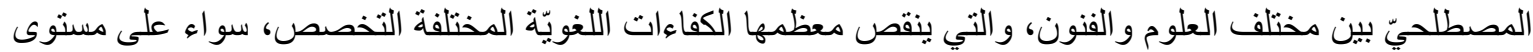

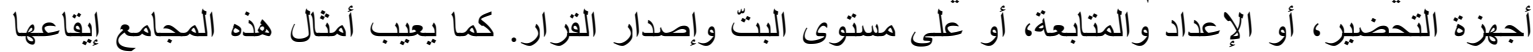

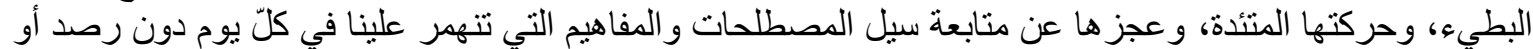

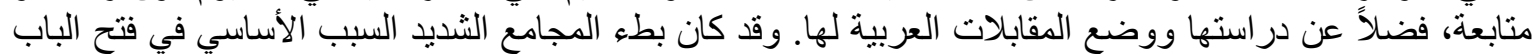

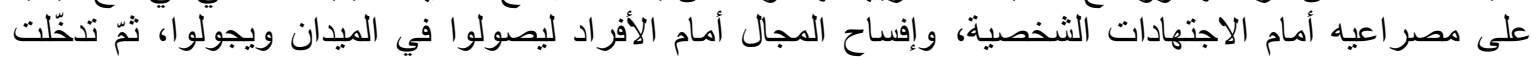

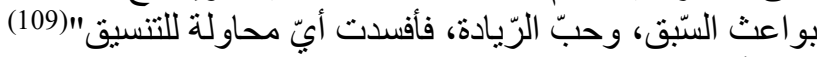

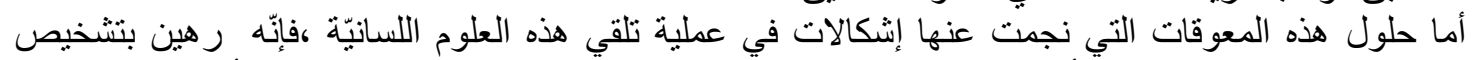

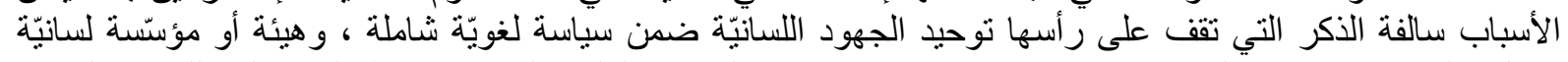

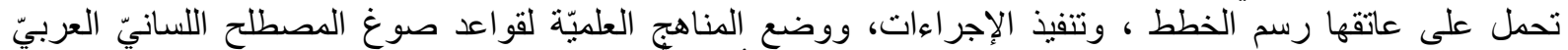

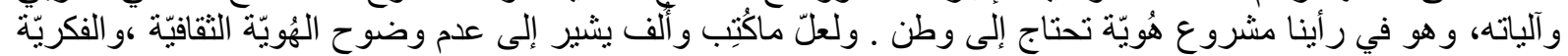

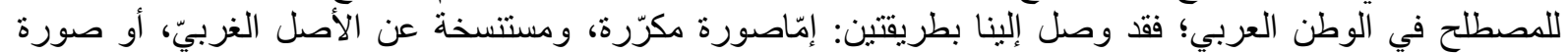

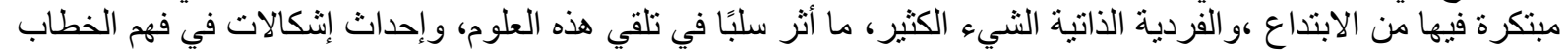

اللسانيّ الحديث عند المتلقيّ العربيّ . الحنيّ

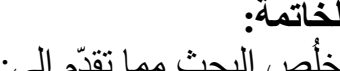

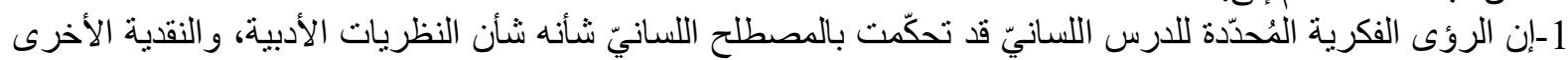

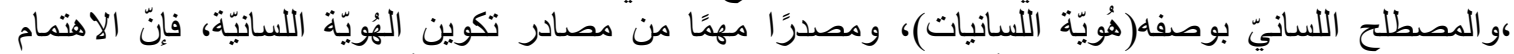

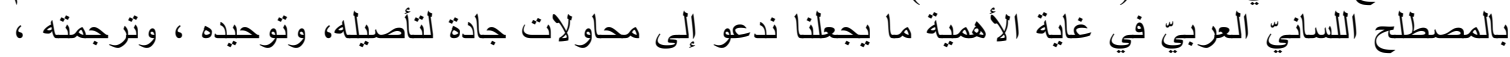
وتعريبه. 2-تأكيد أهمية علاقة المفهوم بالاصطلاح اللسانيّ، و البيئة المُنتجة للمصطلح ، و وعوامل التطور الدلاليّ للمصطلح، وأثر

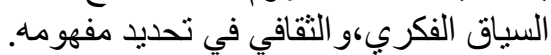

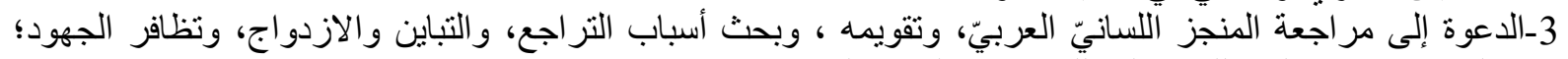

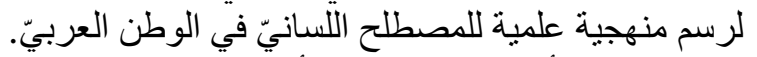

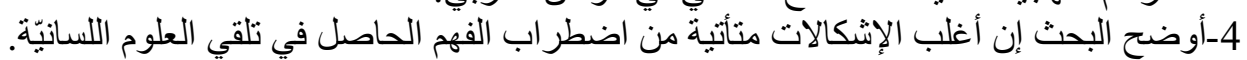

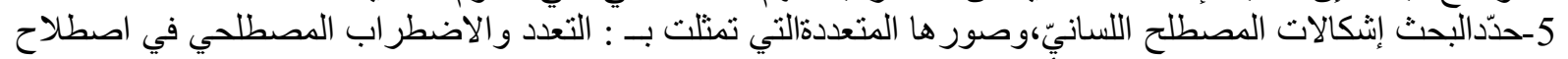

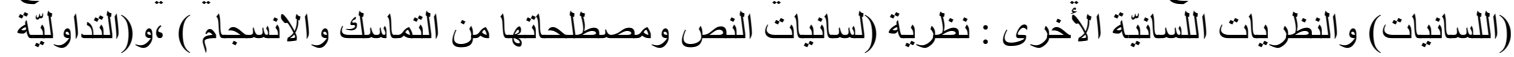

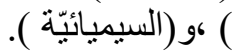
6- بيّن البحث معوقات نرجمة المصطلح اللسانيّ، وأسبابها ، ومظاهرها ،ونأثير الاختلاف الثقافي بين الثقافة العربية والثقافة الغربية . معربت

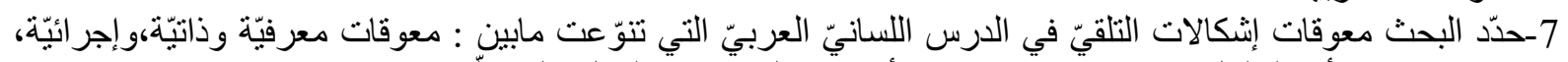

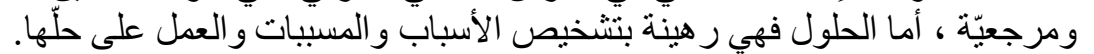

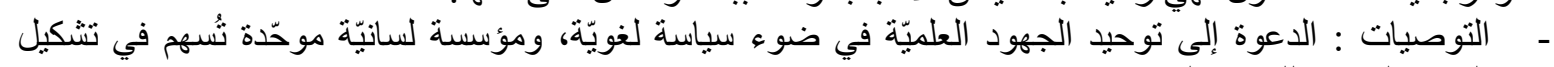
الهُويّة الثقافيّة اللسانيّة العربيّة.

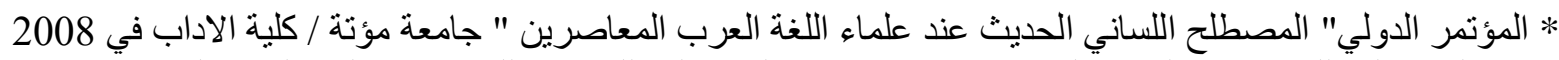

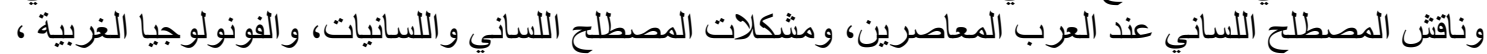

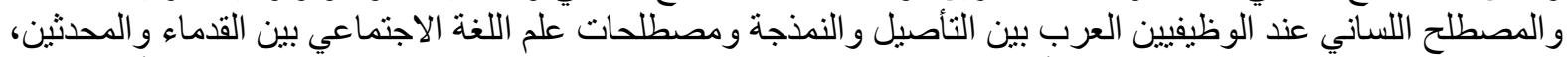

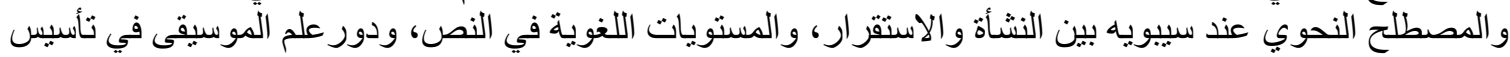

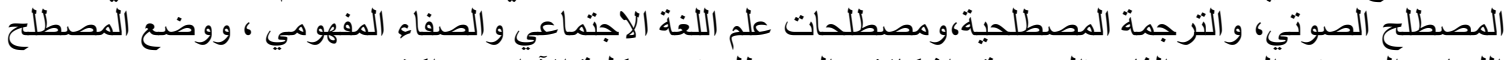

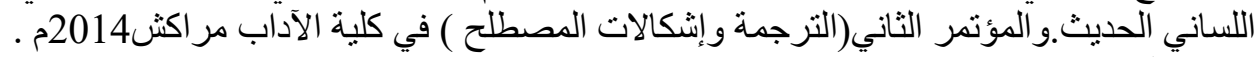

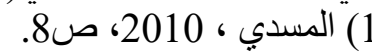

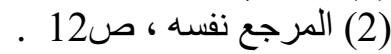

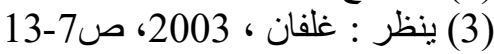

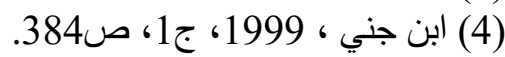

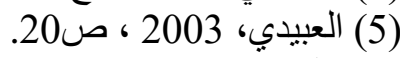

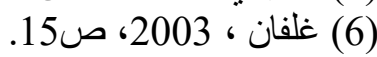
(7) علوي ، و العناتي، 2009 ، 2003 ، ص20 (6) 


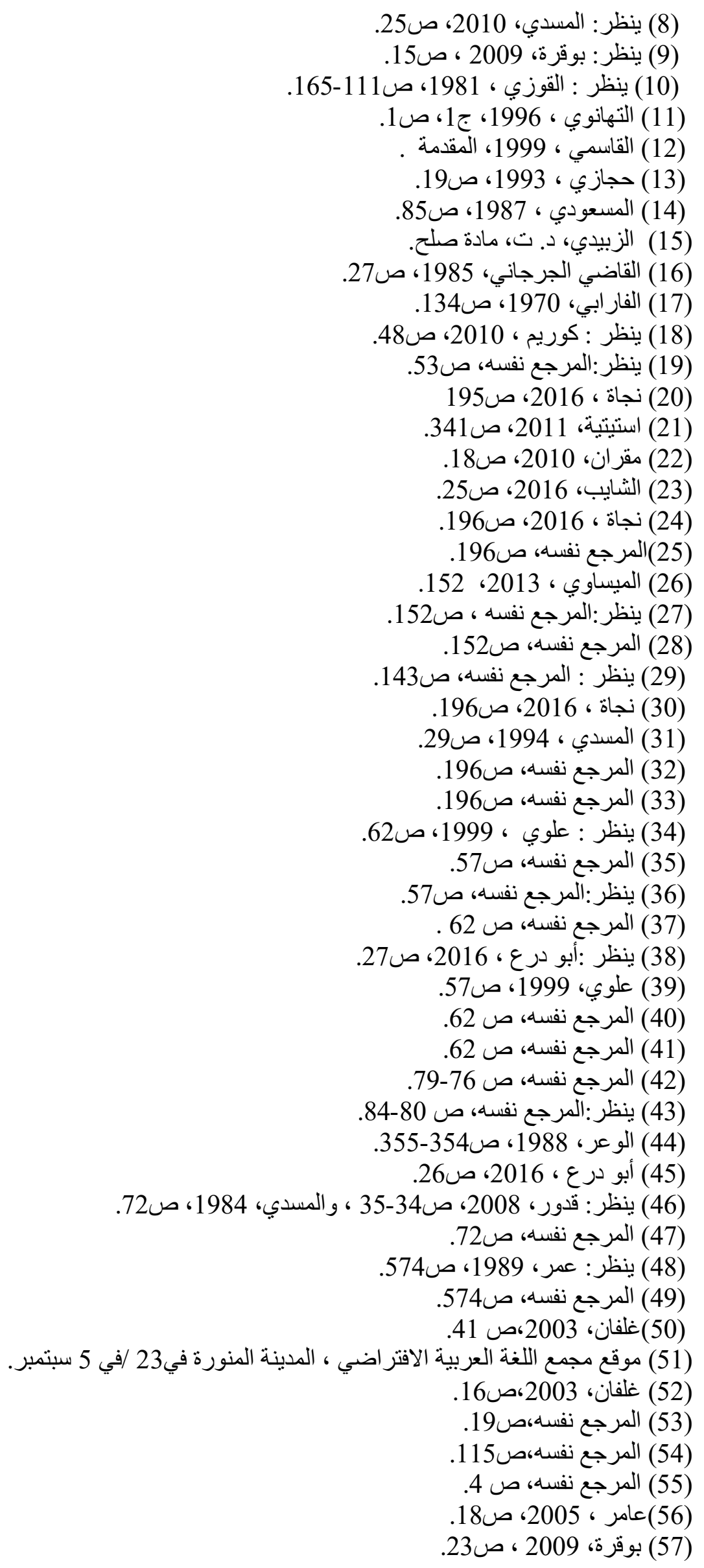




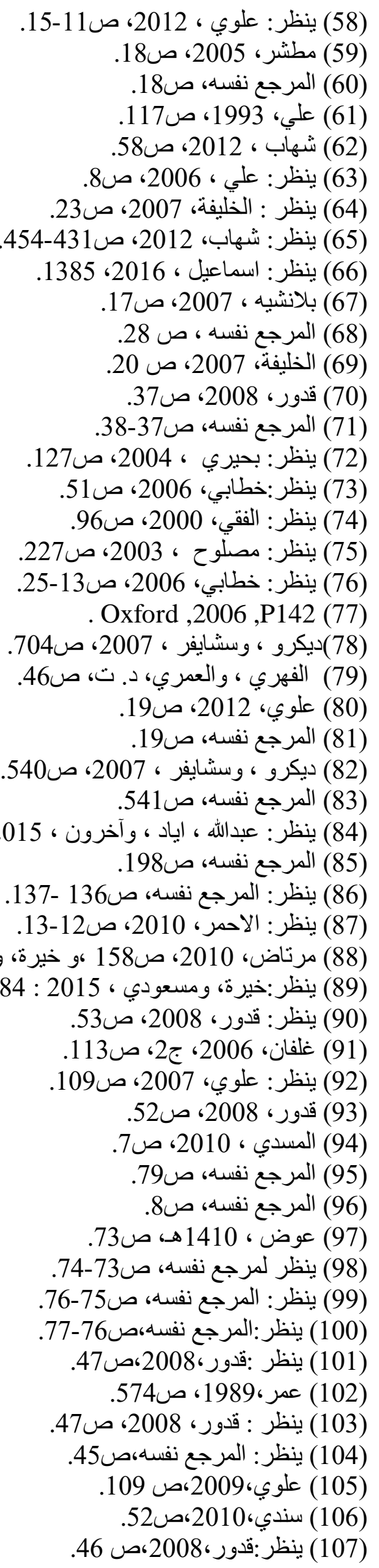


- ابن جني، أبو الفتح عثمان (ت392هـ) (1999): الخصائص، تحقيق محمد علي النجار ، الهيئة المصرية، الطبعة

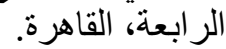
أبو درع ، عبد الرحمن (2016): في اللسانيات العربية واللغة العربية قضايا ونماذج ، دار كنوز المعرفة ، الطبعة

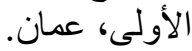

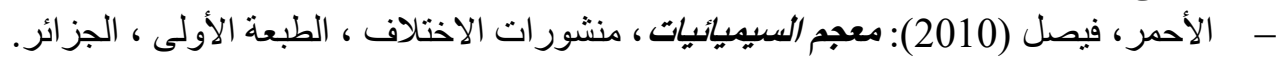

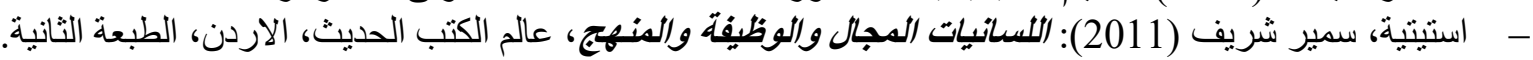

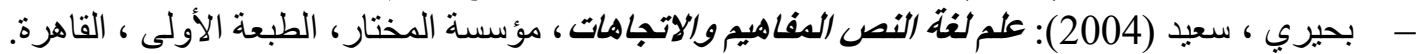

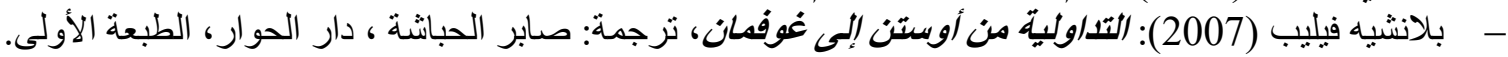

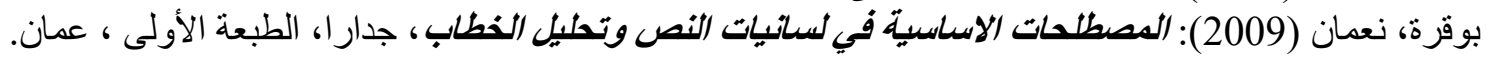

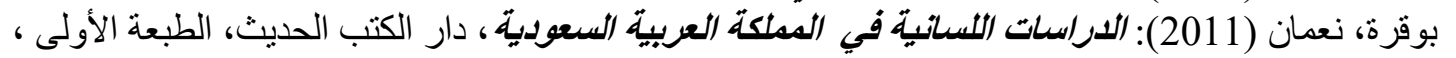

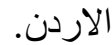

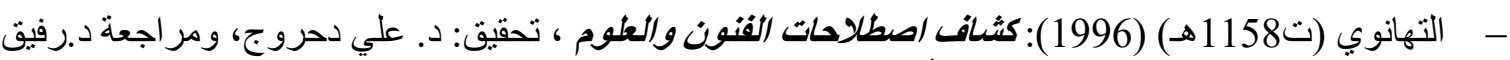

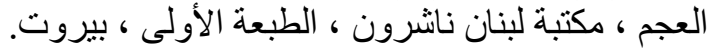

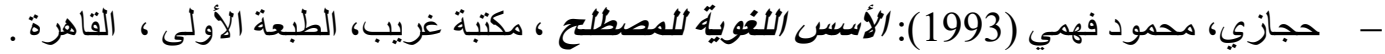

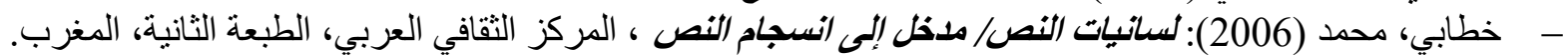

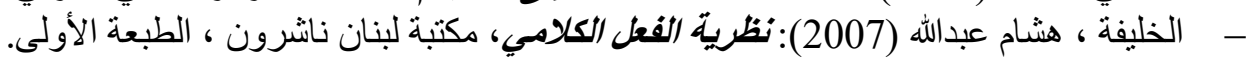

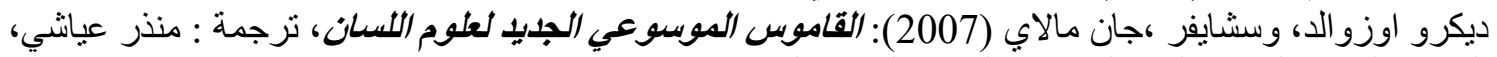

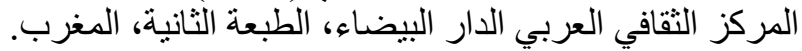

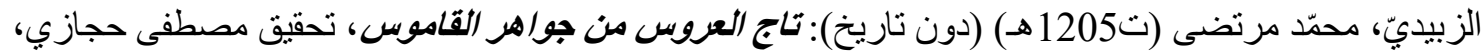
المجلس الوطني للانقافة و الفنون و الآداب. - الثايب، فوزي (2016): محاضرات في اللسانيات، عالم الكتب الحديث ،إربد وجدار للكتاب العالمي ، الطبعة الثنانية، عمان.

العبيدي، رشيد (2003): مباحث في علم اللغة واللسانيات ، دار الثؤون الثقافية، الطبعة الأولى ، العراق.

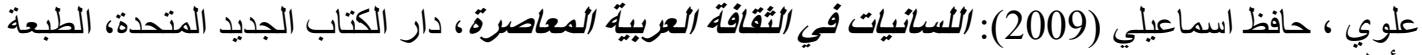
علوي، حافظ اسماعيلي، و العناتي، وليد (2009): اسئلة اللغة اسئلة اللسانيات ، منتور ات الاختلاف ، الدار العربية

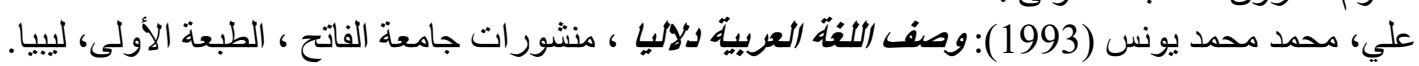

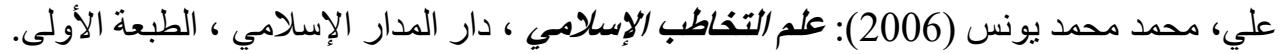

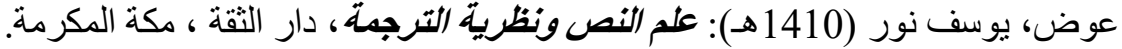

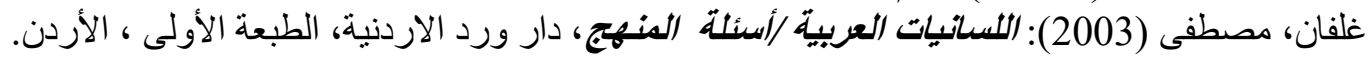

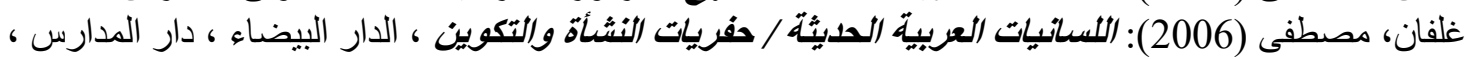

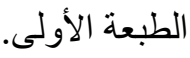

- ـ - الفار ابي، أبو نصر (ت339هـ) (1970): الصروف، تحقيق محسن مهدي، دار المشرق، الطبعة الأولى، بيروت.

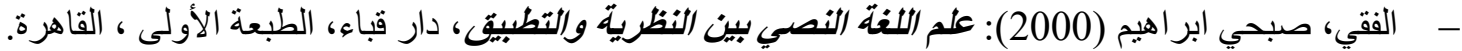

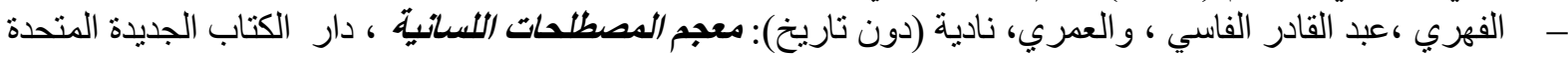

- - القاسمي، علي (1999): علم اللغة وصناعة المعجم ، جامعة الملك سعود، الطبعة الأولى ، السعودية.

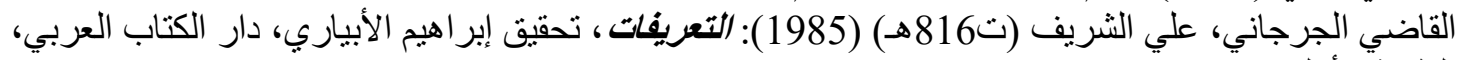

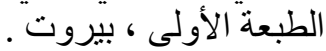

- قدور، د. أحمد (2008): مبادئ اللسانيات ، دار الفكر ، الطبعة الأولى ، دمشق.

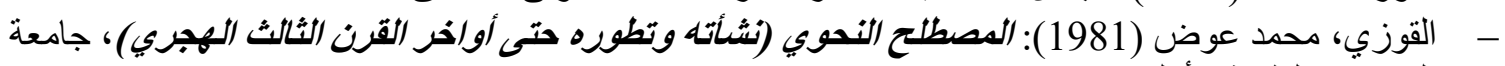
الرياض، الطبعة الأولى. 
- مرتاض ، عبد الملك (2010): نظرية النص الأدبي، دار هومة ، الطبعة الثنانية، الجزائر.

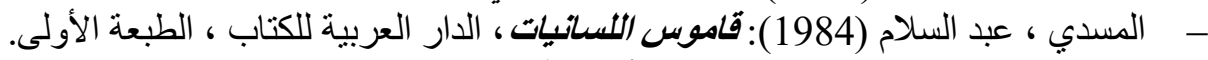

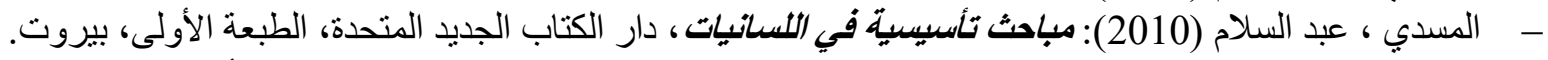

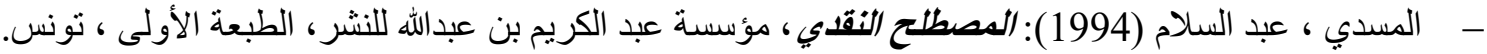

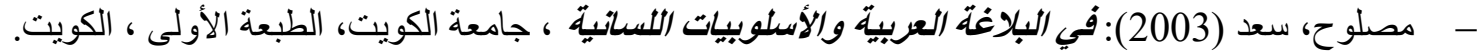

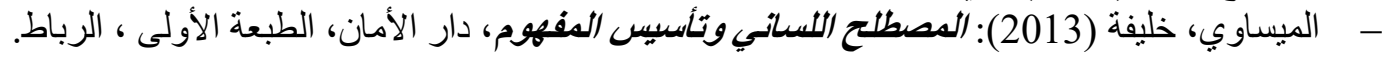

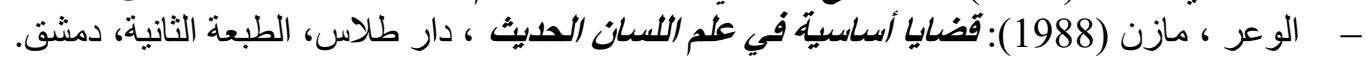
البحوث المنشورة :

- ـ إسماعيل ، هناء محمود (2016): عين الميزان في تداول فعل الكلام عبر الأزمان /قراعة موازنة بين الدرس التراثي

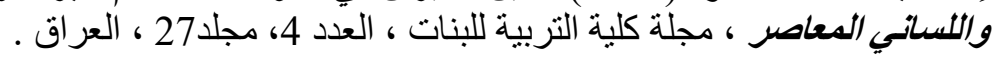

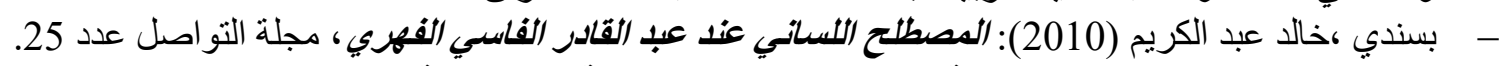

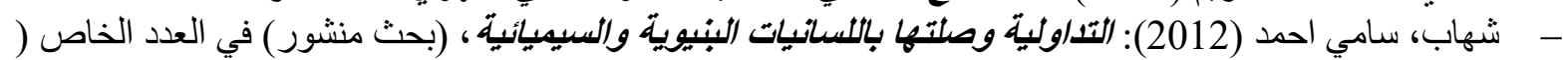

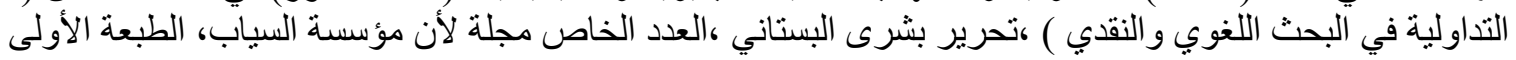
، لندن. عامر ، مجيد مطشر (2005): نظرية النص في البحث اللسانسي العديث (دراسة في إثكالبة المفهوم والتعريف

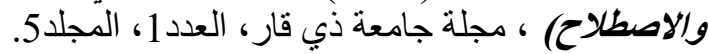

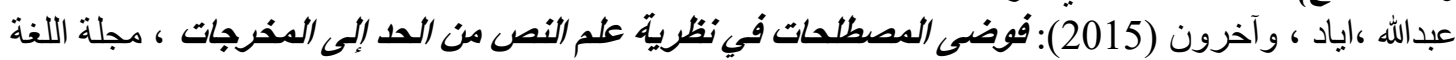

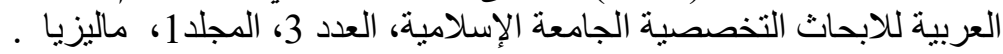

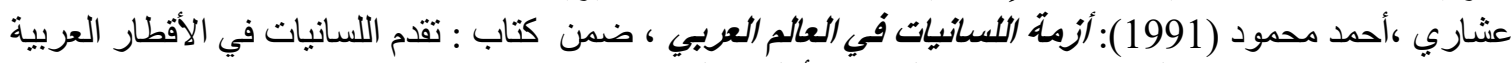

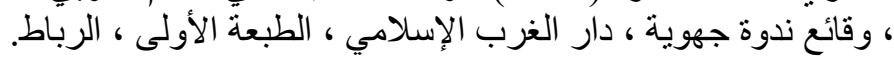

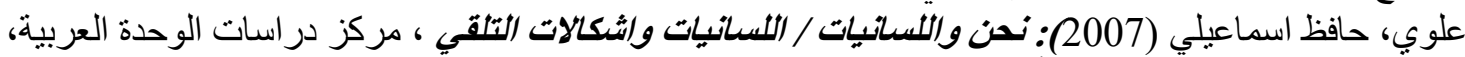

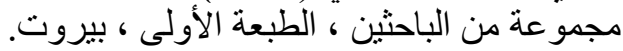

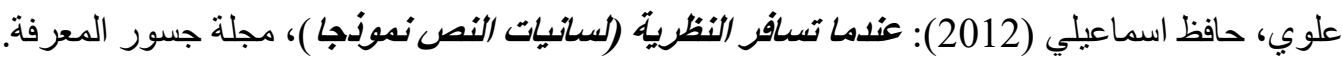

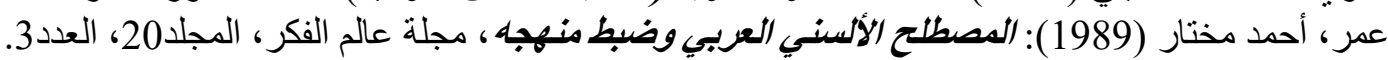

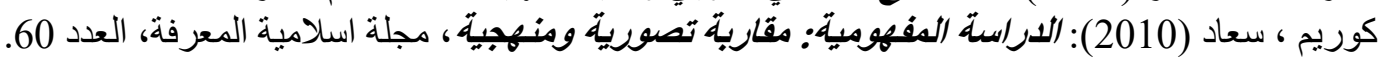

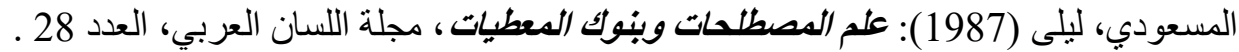

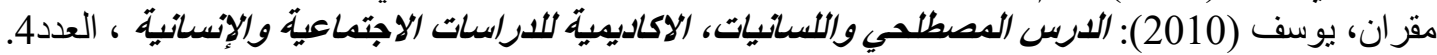

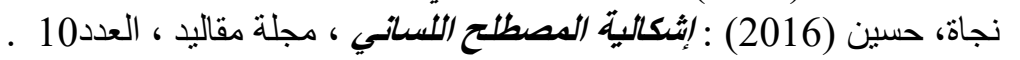

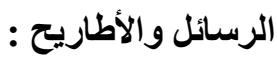

- خيرة، رنيمة ومسعو دي ، فتحية (2015): المصطلح السبيليائس في الخطاب النقلي المعاصر (عبل الملك مرتاض

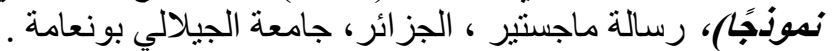

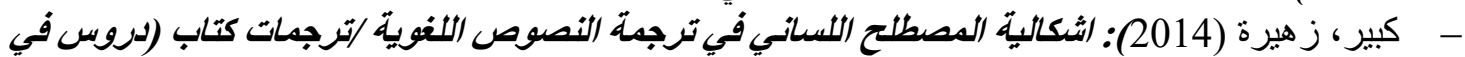

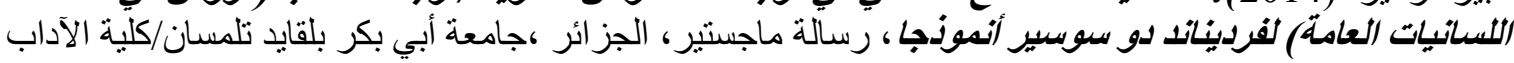

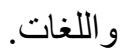

المراجع الأجنبية - Oxford wordpower,university press 2006.

$$
\text { المواقع الاكترونية : موفية }
$$
موقع مجمع اللغة العربية الافتراضي / المدينة المنورة في 23 /في 5 سبتمبر ، 2016م.

\section{References}

\section{/http://almajma3.blogspot.com}

Ibn Jinni, Abu Al-Fath Othman (1999): Characteristics, Investigation of Mohamed Ali AlNajjar, Egyptian Authority, Fourth Edition, Cairo. 
Abu Deraa, Abdul Rahman (2016): In Arabic Linguistics and Arabic Language Issues and Models, Treasures of Knowledge, First Edition, Amman.

Al-Ahmar, Faysal (2010): Dictionary of Semiaments, Diffusion Publications, First Edition, Algeria.

Estate, Samir Sharif (2011): Linguistics Field, Function and Methodology, World of Modern Books, Jordan, Second Edition.

Beheiri, Said (2004): Linguistics of Text Concepts and Trends, Mokhtar Institution, First Edition, Cairo.

Blanche Philippe (2007): Deliberation from Austin to Goffman, translation: Saber Habasha, Dar Al-Hiwar, first edition.

Bougara, Noman (2009): Basic Terminology in Textual and Speech Analysis, Jadra, First Edition, Amman.

Bouguerra, Nouman (2011): Linguistic Studies in Saudi Arabia, Modern Book House, First Edition, Jordan.

Al-Thanawi (1996): Scouts of Arts and Sciences, Achievement: Dr. Ali Dahrouj, Review of Dr. Rafiq Al Ajam, Library of Lebanon Publishers, First Edition, Beirut.

Hijazi, Mahmoud Fahmy (1993): The Language Basis of the Term, Ghareeb Library, First Edition, Cairo.

Khattabi, Mohammed (2006): Linguistics of the Text / Introduction to Text Harmony, Arab Cultural Center, Second Edition, Morocco.

Al-Khalifa, Hisham Abdullah (2007): The Theory of Verbal Function, Lebanon Publishers, First Edition.

Dekro Oswald, Schaeffer, Jean Malay (2007): The New Encyclopedic Dictionary of Tongue Sciences, translated by Munther Ayashi, Arab Cultural Center Casablanca, Second Edition, Morocco.

Al-Zubaidi, Muhammad Murtada (Without a year printed): The crown of the bride from the jewels of the dictionary, by Mustafa Hijazi, National Council for Culture, Arts and Letters.

Alshayeb, Fawzi (2016): Lectures in Linguistics, The World of Modern Books, Irbid and the Wall of the World Book, Second Edition, Amman.

Al-Obeidi, Rachid (2003): Studies in Linguistics and Linguistics, Dar al-Sha`al Al-Kulturiya, First Edition, Iraq.

Alawi, Hafez Ismaili (2009): Linguistics in Contemporary Arab Culture, New United Book House, First Edition.

Alawi, Hafez Ismaili, Al-Anati, Walid (2009): Language Questions Linguistics Questions, Diffusion Publications, Arab Science Publishers, First Edition.

Ali, Muhammad Muhammad Yunus (1993): Description of the Arabic language, Al-Fateh University Publications, First Edition, Libya.

Ali, Muhammad Muhammad Yunus (2006): Islamic Calligraphy, Dar Al Madar Al Islami, First Edition.

Awad, Yousef Nour (1410 A.H): Text Science and Translation Theory, Dar Al-Taqa, Makkah. Galfan, Mustafa (2003): Arabic Linguistics / Curriculum Questions, Dar Ward Jordan, First Edition, Jordan.

Galfan, Moustafa (2006): Modern Arabic Linguistics / Fossilization of Genesis and Formation, Casablanca, Dar Al Madares, First Edition.

Al-Farabi, Abu Nasr (1970): The Letters, Achievement by Mohsen Mahdi, Dar Al-Mashreq, First Edition, Beirut.

Al-Faqi, Subhi Ibrahim (2000): Textual Linguistics between Theory and Practice, Dar Quba, First Edition, Cairo. 
Al-Fihri, Abdelkader Fassi, Omri, Nadia (Without a year printed): Dictionary of Linguistic Terms, New United Book House.

Al-Qasimi, Ali (1999): Linguistics and the Lexicon Industry, King Saud University, First Edition, Saudi Arabia.

Al-Jarajani, Ali Al-Sharif (1985): Definitions, Ibrahim Al-Abiari, Dar Al-Kitab Al Arabi, First Edition, Beirut.

Kadour, d. Ahmad (2008): Principles of Linguistics, Dar Al-Fikr, First Edition, Damascus.

Al-Qawzi, Muhammad Awad (1981): The Grammar Term (Its Origination and Development until the Late Third Century AH), University of Riyadh, First Edition.

Mortad, Abdul Malik (2010): Theory of Literary Text, Dar Houma, 2nd edition, Algeria.

Al-Masadi, Abdel Salam (1984): Dictionary of Linguistics, Arab Book House, first edition.

Al-Masadi, Abdel Salam (2010): Constituent Studies in Linguistics, New United Book House, First Edition, Beirut.

Al-Masadi, Abdessalam (1994): Critical Terminology, Abdelkrim Ben Abdallah Foundation for Publishing, First Edition, Tunisia.

Maslouh, Saad (2003): In Arabic Rhetoric and Linguistic Methods, Kuwait University, First Edition, Kuwait.

Al-Misawi, Khalifa (2013): Terminology and Establishment of Concept, Dar Al-Aman, First Edition, Rabat.

Al-Waar, Mazen (1988): Fundamental Issues in Modern Tongue Science, Dar Tlass, Second Edition, Damascus.

\section{Published Research:}

Ismail, Hanaa Mahmood (2016): The Balance in the circulation of the act of speech through the times / reading a balance between the contemporary literary and literary lesson, Journal of the Faculty of Education for Girls, No.4, Vol. 27, Iraq.

Bessandi, Khaled Abdel Karim (2010): the linguistic term when Abdelkader Fassi Fihri, Journal of communication, No.25.

Shihab, Sami Ahmad (2012): deliberativeism and its connection to structural and semiotic linguistics, (published research) in the special issue (deliberative in linguistic and critical research), Edited by Boshra al-Bustani, Special Issue Magazine for Sayab Foundation, First Edition, London.

Amer, Majid Mutashar (2005): Text Theory in Modern Linguistic Research (A Study on the Problematics of Concept, Definition and Terminology), Dhi Qar University Journal, No.1, Vol. 5.

Abdullah, Iyad et al. (2015): The Chaos of Terminology in the Theory of Text Science from Output to Output, Journal of Arabic Specialized Research, Islamic University, No. 3, Vol. 1, Malaysia.

Ashra, Ahmed Mahmoud (1991): The Crisis of Linguistics in the Arab World, in the book: Progress of Linguistics in Arab Countries, Proceedings of Regional Seminar, Dar Al-Gharb Al-Islami, First Edition, Rabat.

Alawi, Hafez Ismaili (2007): We and Linguistics / Linguistics and Receiving Problems, Center for Arab Unity Studies, Group of Researchers, First Edition, Beirut.

Alawi, Hafez Ismaili (2012): When the theory travels (linguistics of a text model), Journal of Bridges of Knowledge.

Omar, Ahmed Mukhtar (1989): The Arabic Terminology and Its Methodology, Journal of the World of Thought, Vol. 20, No. 3.

Korem, Souad (2010): Conceptual Study: A Conceptual and Methodological Approach, Islamic Knowledge Magazine, No. 60.

Al-Masoudi, Leila (1987): Terminology and Data Banks, Arab Tongue Journal, No. 28. 
Mutashir, Dr. Majeed, (2005): Theory of Text in Modern Linguistic Research (A Study in Problematic Concept, Definition and Idiom), Research published in Thi-Qar University Journal, No. 1, Vol. 5.

Mokran, Youssef (2010): Terminology Lesson and Linguistics, Academy of Social and Human Studies, No. 4.

Najat, Hussain (2016): Problematic Terminology, Journal of Attitude, No. 10.

\section{Theses:}

Khairi, Rnaima and Masoudi, Fethiye (2015): The Semimic Term in Contemporary Critical Discourse (Abdelmalek Murtaza Model), MA, Algeria, University of Gilali, Bonn.

Kabir, Zahira (2014): The problematic of the linguistic terminology in the translation of linguistic texts / Translations of a book (Lessons in General Linguistics) by Ferdinand de Saussure as a model, Master Thesis, Algeria, University of Tlemcen / Faculty of Arts and Languages. 